\title{
A model of meta-population dynamics for North Sea and West of Scotland cod-The dynamic consequences of natal fidelity
}

\author{
Michael R. Heath*, Philip A. Kunzlik, Alejandro Gallego, Steven J. Holmes, Peter J. Wright \\ FRS Marine Laboratory, 375 Victoria Road, Aberdeen AB11 9DB, UK
}

A R T I C L E I N F O

Keywords:

North Sea cod

Migration

Genetics

Spatial modelling

Population structure

\begin{abstract}
A B S T R A C T
It is clear from a variety of data that cod (Gadus morhua) in the North Sea do not constitute a homogeneous population that will rapidly redistribute in response to local variability in exploitation. Hence, local exploitation has the potential to deplete local populations, perhaps to the extent that depensation occurs and recovery is impossible without recolonisation from other areas, with consequent loss of genetic diversity. The oceanographic, biological and behavioural processes which maintain the spatial population structures are only partly understood, and one of the key unknown factors is the extent to which cod exhibit homing migrations to natal spawning areas. Here, we describe a model comprising 10 interlinked demes of cod in European waters, each representing groups of fish with a common natal origin. The spawning locations of fish in each deme are governed by a variety of rules concerning oceanographic dispersal, migration behaviour and straying. We describe numerical experiments with the model and comparisons with observations, which lead us to conclude that active homing is probably not necessary to explain some of the population structures of European cod. Separation of some sub-populations is possible through distance and oceanographic processes affecting the dispersal of eggs and larvae. However, other evidence suggests that homing may be a necessary behaviour to explain the structure of other sub-populations. The consequences for fisheries management of taking into account spatial population structuring are complicated. For example, recovery or recolonisation strategies require consideration not only of mortality rates in the target area for restoration, but also in the source areas for the recruits which may be far removed depending on the oceanography. The model has an inbuilt capability to address issues concerning the effects of climate change, including temperature change, on spatial patterns of recruitment, development and population structure in cod.
\end{abstract}

\section{Introduction}

Cod (Gadus morhua) stocks across the entire geographic range in the North Atlantic were subjected to intense fishing pressure during the 20th century and many suffered well-documented collapses. Subsequent analyses have shown that in some outstanding cases, e.g. the northern cod stock off Newfoundland, the terminal collapse was probably due to a combination of over-fishing and adverse climate (Rose, 2004). In this case, even a total cessation of fishing does not seem to have promoted recovery.

It is feared that a similar train of events to those seen off Newfoundland may be taking place in European waters. The high fishing mortality rates that developed following the so-called gadoid outburst (Cushing, 1984), a period of high productivity for gadoids in the 1960s and 1970s, were considered unsustainable by the early

\footnotetext{
* Corresponding author. Tel.: +44 1224 876544; fax: +44 1224295511.

E-mail address: heathmr@marlab.ac.uk (M.R. Heath).
}

1990s. However, the gap between actual and sustainable exploitation rates continued to widen (Cook et al., 1997), exacerbated by a decline in productivity linked to climate change. In the case of the North Sea, the climatic link is manifest as a negative correlation between recruitment and sea temperature, which is in turn linked to the North Atlantic Oscillation Index (Beaugrand et al., 2003; Brander and Mohn, 2004; O'Brien et al., 2000; Planque and Frédou, 1999). Starting in 2000, various cod stock recovery measures were enacted with the specific aim of allowing as many cod as possible to spawn (Anon., 2000, 2001). ICES finally recommended a total cessation of fishing for cod in certain areas in 2002 (ICES, 2003).

Unlike Newfoundland, cod in European waters are caught largely as part of a multi-species trawl fishery rather than as a single-species targeted fishery. Hence, a total cessation of fishing for North Sea cod was technically difficult to implement without effectively imposing a ban on all trawl fisheries. Instead, a cod recovery plan was devised (Anon., 2004), involving reductions in the permitted number of days fished together with a commensu- 
rate reduction in the total allowable catches of cod. Subsequently, enhanced opportunities to fish for other demersal species were permitted in areas and at times when cod historically constituted a small proportion of the demersal fish assemblage. However, it has long been suspected that cod is a population rich species with complex spatial structure (Sinclair, 1988), and since all of the operational models of North Sea cod were based on whole-stock spatially aggregated dynamics, it was hypothesised that prognoses of the likely impact of spatially structured regulations could, at best, be considered to be only very approximate.

Fishermen have known for centuries that cod migrate annually to particular locations to spawn (Kurlansky, 1999), and tagging studies from across the North Atlantic indicate a high degree of spawning site fidelity among repeat-spawning fish. A high proportion of fish tagged on a spawning site at spawning time and recovered at spawning time in subsequent years are recovered within a short radius of their original tagging location, whilst recoveries at other times of year may have moved considerable distances (Robichaud and Rose, 2001, 2004; Wright et al., 2006a). At the same time, it is clear that there are regional differences in demography and phenotypic properties of fish, which seem to be related to the different spawning regions (West, 1970; Yoneda and Wright, 2004; Olsen et al., 2004; Galley et al., 2006; Wright et al., 2006b). The impression is that cod may exhibit a meta-population structure comprising sub-populations with low rates of inter-mixing due to the passive transport of eggs and larvae, and straying of juveniles and adults.

Tagging studies cannot give insight on the extent to which apparently distinct spawning populations may be reproductively isolated, i.e. whether the return migration of adults to particular spawning sites represents natal fidelity. Early attempts at allozyme based genetic studies indicated that, in the North Sea, cod were a single panmictic unit (Jamieson and Thompson, 1972; Child, 1988). However, more recently, Hutchinson et al. (2001) investigated microsatellite DNA markers and found four genetically distinct groups centred on Bergen Bank, Moray Firth, Flamborough Head and the Southern Bight (Fig. 1), which broadly map onto combinations of the groupings emerging from tagging and otolith shape studies (Wright et al., 2006a; Righton et al., 2007; Galley et al., 2006). Differentiation was weak but significant, and the degree of genetic isolation was weakly correlated with the geographical separation distance. Hence, the implication was that the cycle of spawning, larval drift, juvenile and adult migration is selfcontained over the geographical scale of each of these groups of spawning areas, with relatively little straying. Long-term changes (1954-1998) in genetic structuring have also been examined by DNA analysis of archived otoliths from the Flamborough Head population (Hutchinson et al., 2003). These data indicated marked genetic changes and loss of allelic diversity during a period of significant decline in abundance.

The key conclusion from the combination of tagging, genetic, microchemistry and morphometric studies on cod in European waters is that the essential spatial scale of breeding populations is smaller than the current stock assessment units, and is defined by some function of larval drift and juvenile and adult migration patterns. As a consequence, recovery plans involving spatially structured fishery regulations may have unforeseen outcomes depending on their placement, and any benefits may not be distributed equally over the current assessment regions.

Our objective in this study was to examine the consequences of different assumptions about natal fidelity for regional dynamics and population structuring. Hence we required to track the development of genetic populations. To achieve this we developed a model which represented multiple demes by means of age-based discrete time methodology, with a spatial representation of the physical oceanographic and fish behaviour patterns that maintain spatial organisation, as well as the spatial patterns of production (recruitment and growth) and mortality (natural and fishing). This type of modelling represents a significant departure from the current modelling approaches as applied to fish stocks.

\section{Methods}

\subsection{Model description}

The domain of our model was a subset of the region covered by the annual ICES stock assessments of the North Sea, Skagerrak and eastern Channel (ICES Divisions IIIa (Skagerrak), IV \& VIId) and west of Scotland (Division VIa); namely the North Sea and west of Scotland (Divisions IV and VIa). Based on tagging data, geographical distributions of fish from surveys and landings, and studies of fish morphology and microchemistry (Wright et al., 2003, 2006b; Metcalfe et al., 2005; Galley et al., 2006) we identified 10 potentially distinct groupings, or sub-stock units of cod in this region, each associated with a geographically fixed spawning area. Our model was configured to represent each of these (Fig. 1). ICES Divisions IIIa (Skagerrak) and VIId were not explicitly included in this analysis although implicitly Division VIId is incorporated in area 10 (Dogger Bank/Southern Bight) and Division IIIa (Skagerrak) is incorporated in area 8 (Fisher Bank).

The fish in each sub-stock unit were defined as having all been born in the same spawning sub-area of the model domain. Hence, we refer to the sub-stock units as natal populations, and to their associated sub-areas of origin as natal areas. However, there was no requirement in the model that fish should necessarily return to spawn in their natal area, although this was a structural option, so that the group of fish spawning in a sub-area could in principle be composed of fish from a variety of natal populations. But, the offspring of all fish spawning in a sub-area belonged to the 'local' natal population for the rest of their lives, regardless of the natal origin of the parents or where they subsequently spawned as adults. Straying, and the processes which might influence straying, were therefore key structural aspects of the system. Hence, the model tracked annual cohorts of fish of distinct geographic origin, and was capable of simulating the proportion of fish spawning in an area which were themselves of local origin. The model could therefore provide an assessment of the scope for genetic isolation, subject to a range of alternative interpretations of the processes controlling migration and interaction between sub-stocks.

Within each natal area we identified firstly, a set of $1 / 4^{\circ}$ latitude $\times 1 / 2^{\circ}$ longitude rectangles representing cod spawning areas, on the basis of egg survey data and catches of spawning fish, and secondly a set of rectangles representing suitable nursery habitat for juvenile cod based on trawl survey data (Fig. 1). Rectangles recorded as containing either $>2$ cod eggs $\mathrm{m}^{-2}$ in plankton surveys, or $>1$ spawning fish per hour in trawl surveys were designated as spawning sites. Similarly, rectangles in which age 1 concentrations of $\operatorname{cod} \geq 0.01 \mathrm{~m}^{-2}$ were encountered at any time during annual trawl surveys in February, were designated as nursery sites into which pelagic juveniles could settle.

\subsection{Population dynamics}

We adopted an age-structured cohort approach to simulating the number and state (body length, maturity) of fish in each natal population. The number of homogeneous age structured populations was defined as $P=10$. Each population $(n, n=1-P)$ contained all fish which were born in the same natal area $(J, J=1-P)$ of the model domain. Within each population, the number of fish $(N)$ in 

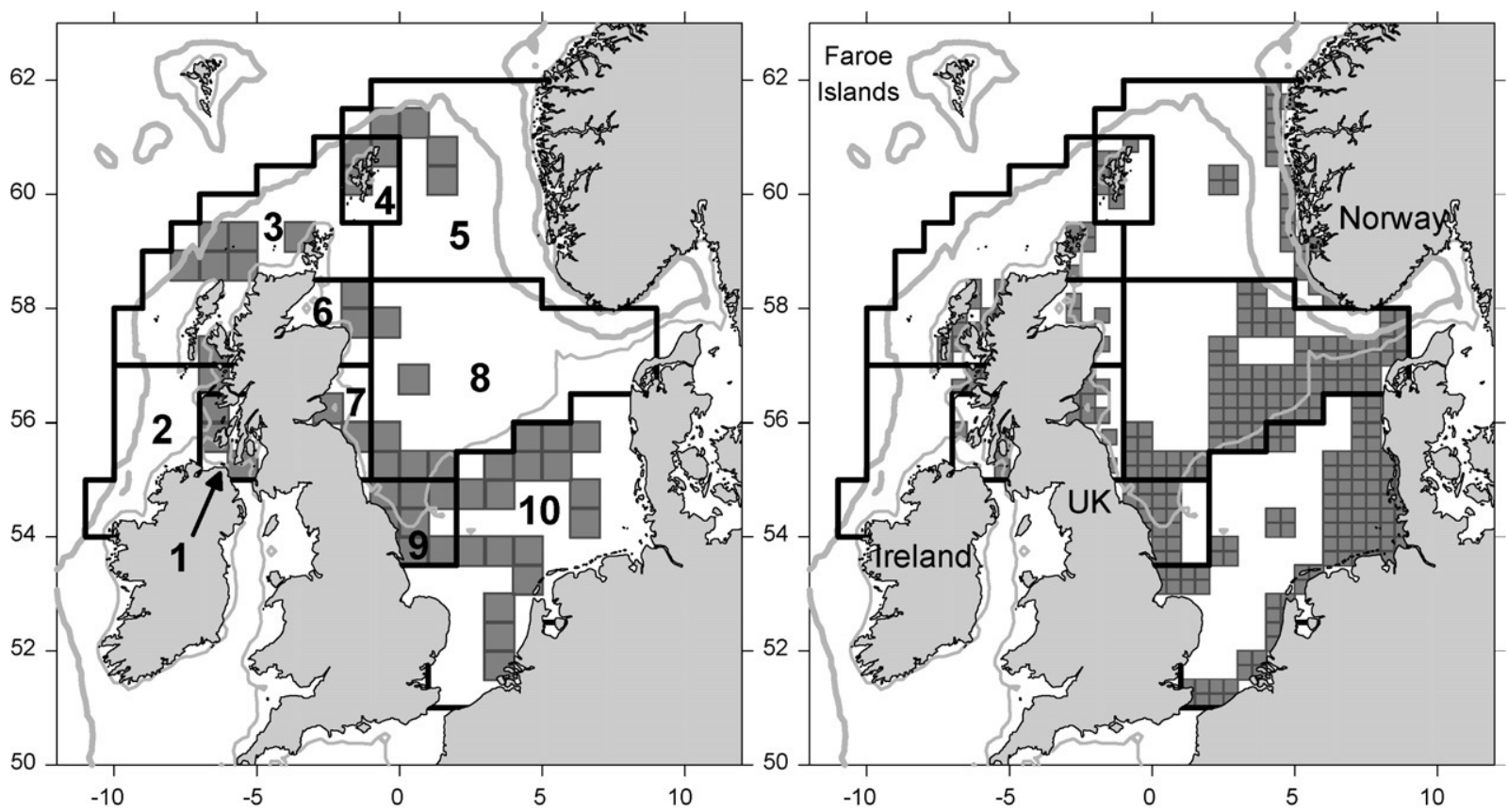

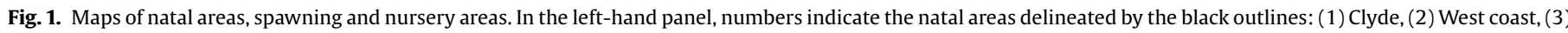

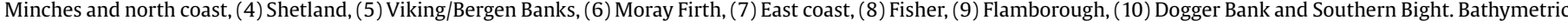

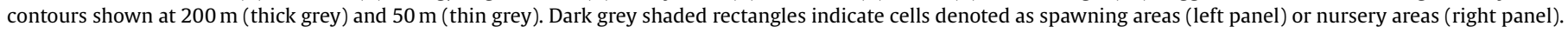

each annual age class ( $a$, where $a$ was an integer between 0 and 20) was further divided into mature $\left(N_{\text {mature }}\right)$ and immature $\left(N_{\text {immature }}\right)$, and their numbers updated at monthly intervals $(m=0-12$, where 0 denotes 1 January, 1 denotes 31 January, and 12 denotes 31 December) through each calendar year $(y)$ according to the total mortality rate $\left(Z=\right.$ natural mortality $(M)+$ fishing mortality $(F)$, month $\left.^{-1}\right)$. Natural mortality was applied from the age of transition between drifting larval phase and settled juvenile (recruitment) onwards. Fishing mortality was a prescribed value depending on year and age, and also on month and geographical location. Within each natal population, fish were potentially distributed across any number (up to $P$ ) of the nursery, spawning area and feeding areas depending on time of year, larval drift patterns, and post-settlement migration behaviours.

For mature fish in a given natal population $(n)$ and destined to spawn in a given spawning area $(j=1-P)$, at each time step:

$N_{\text {mature }_{(n, y, m, a j)}}=\exp \left(\ln \left(N_{\text {mature }_{n, y, m-1, a j}}-M_{\text {mature }_{n, y, m, a}}-F_{y, a, m, j}\right)\right)$

The natural mortality rate $M_{\text {mature }_{y, m}, a}$ was a continuous function of body length during the month $m$ (see Appendix A). The fishing mortality rate $F_{y, a, m, j}$ depended on year $(y)$, age $(a)$, month $(m)$ and which spawning area $(j)$ the fish were associated.

For immature fish:

$$
\begin{aligned}
N_{\text {immature }_{(n, y, m, a, c)}=} & \exp \left(\operatorname { l n } \left(N_{\text {immature }_{n, y, m-1, a, c}}-M_{\text {immature }_{n, y, m, a, c}}\right.\right. \\
& \left.\left.-F_{y, a, m, c}\right)\right)
\end{aligned}
$$

where $c$ denoted the nursery areas $(c=1-P)$. The natural mortality rate $M_{\text {immature }_{y, m, a, c}}$ was a continuous function of body length during the month $m$, as for the mortality rate of mature fish, but additionally included a nursery area specific dependent density dependent component (see Appendix A).
The total number of fish at age in the natal population was then given by:

$N_{n, y, m, a}=\sum_{j=1}^{j=P} N_{\text {mature }_{n, y, m, a j}}+\sum_{c=1}^{c=P} N_{\text {immature }_{n, y, m, a, c}}$

At the end of each calendar year $(m=12)$ all the fish in each age class were transferred to the initial conditions $(m=0)$ for next oldest age class. The first age class $(a=0)$ was thus vacated, pending recruitment of the young-of-the-year on a given date, and all fish in the oldest class ( $a=20)$ were killed off. During the transfer to next oldest age class, a proportion of immature fish were transferred to the mature state, according to the change in proportion mature at age $\left(Q_{n, y, a}\right)$ in the natal population resulting from the increment in age. $Q_{n, y, a}$ was a function of body length on 1 January each year (see Appendix A):

$N_{\text {immature }_{n, y, m=0, a, c}}=N_{\text {immature }_{n, y-1, m=12, a-1, c}} \times \delta_{n}$

where $\delta_{n}=\left(1-Q_{n, y, a}\right) /\left(1-Q_{n, y-1, a-1}\right)$ for $Q_{n, y-1, a-1}<1$ and $\delta_{n}=0$ for $Q_{n, y-1, a-1}=1$

$$
\begin{aligned}
\sum_{j=1}^{j=P} N_{\text {mature }_{n, y, m=0, a j}=} & \sum_{j=1}^{j=P} N_{\text {mature }_{n, y-1, m=12, a-1 j}} \\
& +\sum_{c=1}^{c=P}\left(N_{\text {immature }_{n, y-1, m=12, a-1, c}} \times \delta_{n}^{\prime}\right)
\end{aligned}
$$

where $\delta_{n}^{\prime}=\left(Q_{n, y, a}-Q_{n, y-1, a-1}\right) /\left(1-Q_{n, y-1, a-1}\right)$ for $Q_{n, y-1, a-1}<1$ and $N_{\text {immature }_{n, y-1, m=12, a-1, c}} \times \delta_{n}^{\prime}=0$ for $Q_{n, y-1, a-1}=1$.

The distribution of mature fish across spawning areas $(j)$ was then reassigned according to a straying proportion for fish which had been mature in the previous year (repeat spawners), and a firstspawning migration pattern for fish which had been immature in the previous year. These straying and migration terms are described 
later, but briefly, they assigned the area of next spawning on the basis of spawning or nursery area assignment in the previous year.

\subsection{Recruitment}

Fish were recruited to the first age class $(a=0)$ of each natal population on a fixed date each year (1 August, $m=8$ ), representing the timing of settlement of pelagic phase juveniles to the demersal habitat in each nursery area. The number of fish recruiting to each natal population was determined from the annual population fecundity of all the fish spawning in each spawning area (equivalent to the annual egg production, see Appendix A), and the proportion of these eggs surviving the drift from release to settlement in each nursery area. This proportion was simulated by an off-line particletracking model which modelled the dispersal, growth and survival of eggs and larvae, subject to the year-specific ocean circulation and temperature conditions. For each natal population, the number of potential recruits was then the sum of surviving pelagic juvenile numbers arriving at all nursery areas on settlement date. However, the actual number recruiting to the age-structured natal population from each nursery area was reduced by a settlement mortality term representing competition for resources in the nursery area. This increased as a function of the total number of juveniles of all natal origins attempting to settle at each nursery area. Thus, the settlement mortality introduced a density dependence acting both within and between natal populations (see Appendix A).

\subsection{Development}

The body length of fish was updated at monthly intervals, coincident with the updating of per capita abundance. The change in body length over time was represented by the von Bertalanffy growth equation (von Bertalanffy, 1938). All fish in an annual cohort of a natal population inherited the same von Bertalanffy growth parameters which they retained throughout life, regardless of their subsequent migrations. The characteristic growth parameters of fish in each natal population were determined principally from analysis of length and age data collected during annual trawl surveys (see Appendix A).

The proportional distribution between immature and mature state, which was updated annually on 1 January, depended on a continuous function of body length (see Appendix A). For mature fish, female fecundity was also a continuous function of body length (see Appendix A).

\subsection{Migration}

We represented four types of fish movement in the model: (1) passive drift of eggs and larvae, (2) "first-spawning migration" of virgin fish to their first spawning site, (3) annual migration of mature fish between spawning sites and a summer feeding area, and (4) straying of repeat spawning fish from their area of first spawning to other spawning areas (Fig. 2).

Whilst spawning site fidelity of repeat spawning fish and seasonal migrations of adult cod were relatively easily inferred from tagging data, there were few data for inferring migrations of juveniles and no basis for determining the extent of natal fidelity involved in spawning site selection by fish. Spawning site fidelity of repeat spawning fish was therefore parameterised in the model on the basis of tagging data, but alternative views of first-spawning migrations and natal fidelity were treated as structural variants of the model (Fig. 2). In reality, these variants might not be mutually exclusive in their representation of first-spawning migration behaviours across the model region, but their performance relative to our understanding of the spatial
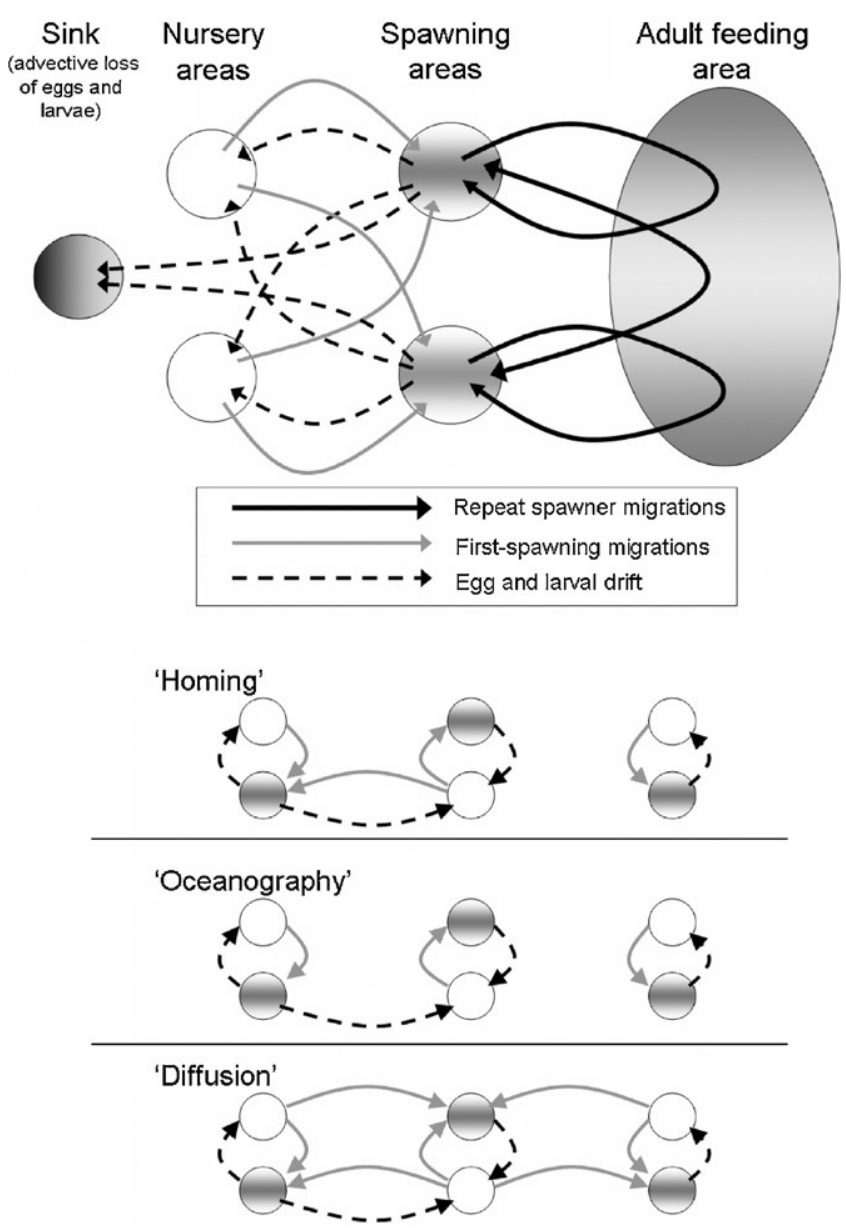

Fig. 2. Schematic of drift and migration connections between areas occupied by fish in different life stages. Upper panel: connections between nursery, spawning and adult feeding areas, illustrated by an example of two spawning and nursery areas, with a single shared feeding area. Shading patterns denote nursery, spawning, feeding, and sink areas for eggs and larvae. Arrows show movements of fish from source to destination areas due to egg and larval drift, first-spawning migration, and repeat spawner migration. Lower three panels illustrate the connections between three spawning and nursery areas for different structural variants of the model representing scenarios of first-spawning migration behaviour denoted by 'homing', 'oceanography' and 'diffusion'. In these panels the positioning of spawning and nursery areas is indicative of spatial proximities. Shading and arrow patterns as in the upper panel (open circles, nursery areas; grey shaded circles, spawning areas; dashed arrows, egg and larval drift; grey arrows, first-spawning migration). Note that the pattern of egg and larval drift is the same in each case, but in the homing scenario first-time spawners return to their natal spawning ground. In the oceanography scenario first-time spawners remain at the spawning area closest to their nursery area regardless of natal origin. In the diffusion scenario, first-time spawners disperse to spawning areas adjoining their nursery area regardless of natal origin.

dynamics of abundance was a key aspect of the analysis of the model.

\subsection{Passive drift}

Eggs and larvae produced at spawning rectangles in the model were dispersed to nursery rectangles according to simulated ocean circulation which drove the pattern of passive transport in a given year. By the end of the pelagic juvenile stage each nursery area (made up of the set of nursery rectangles contained within a subarea) was populated with young fish of a variety of natal origins depending on transport patterns. We allowed for different rates of fishing mortality in the various nursery areas, where the juveniles remained until they attained maturity. 


\subsection{First-spawning migration}

The juveniles in each nursery area were assigned a future spawning affiliation to represent their eventual first-spawning migration. This assignment was one of the key structural variants in the model (Fig. 2) and the consequences for the overall population dynamics of varying the degree of natal spawning fidelity was one of the features of the model which we wished to explore. The proportions of individuals in each natal population at each nursery area destined to spawn at each spawning area $\left(V_{n, c, j}, \sum_{c=1}^{c=P} V_{n, c, j}=1\right)$ were set to mimic one of three first-spawning migration scenarios. In the first scenario, which we refer to as the 'homing scenario', all fish migrated to their spawning area of origin to spawn for the first time. Thus first spawning fish were faithful to their natal origin. In the second scenario, which we refer to as the 'oceanography scenario', the future first spawning area assignment of juveniles was set to equal their nursery area regardless of their origins. Thus, in this scenario the distribution of first spawning fish within a natal population was dictated solely by ocean circulation. In the third scenario, which we refer to as the 'diffusion scenario', a proportion of fish in each nursery area emigrated to adjoining areas to spawn for the first time. The remainder behaved as in the oceanography scenario. For those fish that emigrated in the diffusion scenario, the distribution across destination spawning areas was determined from the proportion of source nursery area boundary in common with each destination spawning area. The proportion emigrating from the nursery area ( $\mathrm{pm}$ ) was treated as a sensitivity testing parameter. Thus, there was scope for cross-breeding between natal populations among first-time spawners in the oceanography and diffusion scenarios, depending on oceanographic dispersal and the emigration parameter pm, but not in the homing scenario.

\subsection{Annual migration}

We simplified the annual migration behaviour of mature fish by specifying that they spend a fixed proportion of each year of mature life in the vicinity of a chosen set of spawning rectangles, and the remainder of the year feeding elsewhere. The timing of migrations between spawning and feeding areas varied between spawning areas, and was estimated from the mean and standard deviation of spawning date in each natal area. Spawning dates were derived from a combination of the recorded dates of capture of maturity states of female cod (areas 1-6) (see methodology of Heath and Gallego, 1998), and egg survey data published by Brander (1994) (areas 7-10) (Table 1). The duration of residency in the spawning area was taken to be 6 standard deviations around the mean spawning date.

\subsection{Straying of repeat spawners}

Subsequent to first spawning, fish were allowed to change their spawning affiliation on an annual basis to mimic the straying pat- terns revealed by tagging data. This straying was independent of natal population and represented the accuracy with which fish returned to the same spawning site each year, not the fidelity of fish to their natal origin. A matrix $\left(S_{a, j \text {-previous } j \text {-next }}\right)$ specified the proportion of mature fish of age a which, having spawned in area $j$-previous in the current year, will spawn in area $j$-next in the following year. Hence, for each value of $a$ and $j$-current,

$\sum_{j \text {-next }=1}^{j \text {-next }=P} S_{(a, j \text {-previous } j \text {-next })}=1$

Spawning area affiliations were assigned on 1 January each year, in advance of the first appearance of fish in any of the spawning areas.

The matrix $S$ was parameterised with data on the recapture locations of fish tagged during spawning months (January-April) and retrieved during the same period in subsequent years. Data and methods for standardising tag recoveries for catch rates in the fishery are given in Wright et al. (2006a). A $\chi^{2}$-test was used to test the null hypothesis that there is no difference between age classes in the proportion of fish tagged in one area and recovered from other areas. The average stray proportion (ps) was used to calculate the expected frequency for each age.

\subsection{Spatial and temporal distribution of fishing mortality}

Estimating spatial and temporal variability in the fishing mortality rate $(F)$ on cod is highly problematic. For the North Sea and west of Scotland, where the fishery is multi-species and conducted by a variety of fleets from a variety of nations, reliable spatially resolved data on effort are extremely difficult to compile, and in any case are not simply related to mortality rates. Landings data are more readily available, but also not easily related to mortality. Hence, we analysed trawl survey data collected in February/March each year to estimate the total mortality of age classes between successive annual surveys, and used these to apportion the ICES regional fishing mortality rates between our model areas.

The ICES stock assessments provide year-by-year hindcasts of the regional scale annual averaged fishing mortality in the North Sea (ICES areas IIIa (Skagerrak), IV and VIId) and west of Scotland (ICES area VIa) for each age class of cod (ICES, 2005, 2006). We used 1980-1999 mean fishing mortality rates at age from the versions of the ICES assessments which included discards in the catch records, or scaled multiples of these, as the basis for setting the absolute level of mortality in our simulations, and developed temporal and spatial scaling on the basis of landings and survey data. The assessment outputs provide fishing mortality rates up to age 6 (age 7 for area VIa), so we assumed a constant fishing mortality rate over all older age classes.

For each region $(R)$ ( $R=$ "west of Scotland" for model areas $1-3, R=$ "North Sea" for model areas 4-10), the ICES annual fish-

Table 1

Summary of data used to assign spawning months to fish in each natal population

\begin{tabular}{|c|c|c|c|c|c|c|c|}
\hline Fish spawning in area & Mean date & S.D. of date & $\begin{array}{l}\text { Number of } \\
\text { fish analysed }\end{array}$ & Source & $\begin{array}{l}\text { Month of arrival } \\
\text { in spawning area }\end{array}$ & $\begin{array}{l}\text { Spawning } \\
\text { month }\end{array}$ & $\begin{array}{l}\text { Month of leaving } \\
\text { spawning area }\end{array}$ \\
\hline Area 1-3 & 68.2 & 8.2 & 740 & $\begin{array}{l}\text { 1999-2004 unpublished maturity data } \\
\text { (P. Wright) }\end{array}$ & February & March & April \\
\hline Area 4 and 5 & 69.3 & 18.4 & 394 & $\begin{array}{l}\text { 1999-2004 unpublished maturity data } \\
\text { (P. Wright) }\end{array}$ & January & March & May \\
\hline Area 6 & 62.6 & 14.1 & 149 & $\begin{array}{l}\text { 1999-2004 unpublished maturity data } \\
\text { (P. Wright) }\end{array}$ & January & March & April \\
\hline Area 7-9 & 68 & 20 & & West central-egg data, Brander (1994) & January & March & May \\
\hline Area 10 & 63 & 15.9 & & $\begin{array}{l}\text { German Bight-egg data, Brander } \\
\text { (1994) }\end{array}$ & January & March & April \\
\hline
\end{tabular}


ing mortality rate by age class, averaged over 1980-1999, was first expressed as a monthly rate $\left(F_{\text {monthly }}=F_{\text {annual }} / 12\right)$. For the mature age classes, the temporal distribution of the regional fishing mortality $\left(\operatorname{ICESF}_{a, \mathrm{R}}\right)$ between the period of the year spent in the spawning areas $\left(\left(\mathrm{ICESF}_{a, \mathrm{R}}\right)_{\text {spawning }}\right)$ and the period spent on feeding grounds ((ICESF $\left.\left.{ }_{a, \mathrm{R}}\right)_{\text {feeding }}\right)$, was apportioned according to the temporal distribution of landings, such that the annual average rate corresponded with that from the assessments. For immature fish the regional rate of fishing mortality was assumed to apply throughout the year.

Spatial variations in fishing mortality on mature fish during the feeding period of the year were not resolved in the model. All mature fish associated with spawning areas 1-3 were subjected to the feeding period rate of mortality corresponding to the west of Scotland assessment, and mature fish associated with areas 4-10 were subjected to the North Sea regional rate during the feeding period. However, the spawning period rates of fishing mortality in the North Sea and west of Scotland regions $\left(\left(\mathrm{ICESF}_{a, \mathrm{R}}\right)_{\text {spawning }}\right)$ were further resolved to spatial areas according to catch rates from trawl surveys. Similarly, fishing mortality on immature fish was resolved to spatial areas.

Each February since 1983, the ICES International Bottom Trawl (IBTS) survey of the North Sea has sampled fish by means of standardised tows with the GOV trawl from an international fleet of survey vessels. Individual lengths of catches of all species are measured at sea and ages of key species determined by length stratified sub-sampling for otoliths. Data on catch per unit effort (CPUE, numbers $\mathrm{h}^{-1}$ ) at age (a) of cod in each sampling tow in the North Sea were obtained for years $(y)$ 1983-2004 from the ICES data centre. An equivalent survey of the west of Scotland region (ICES area VI) is carried out in March each year, immediately following the IBTS, and these data (1985-2004) were available at the Marine Laboratory Aberdeen. CPUE at age in each survey year from both surveys was spatially averaged over each of our 10 model areas $(J)$, according to the locations of each tow to give an estimate of density. The methodology for spatial averaging has been described by Holmes et al. (2008).

For each of the 10 areas we estimated the average over the survey series of age-specific total mortality rate $\left(Z_{a J}, \mathrm{y}^{-1}\right)$ in each of our model sub-areas:

$Z_{a, J}=\overline{\ln \left(C P U E_{y+1, a+1, J}\right)-\ln \left(C P U E_{y, a, J}\right)}$

where $\operatorname{CPUE}_{y, a_{J}}$ was the area averaged catch per unit effort in year $y$ of age a in area $J$. Assuming that age-specific natural mortality $(M)$ does not vary systematically between sub-areas, we then scaled the age-specific total mortality rates for each area to represent fishing mortality rates $(F=Z-M)$, such that after abundance weighting each value, the average over each ICES assessment regions (R) equalled the corresponding regional fishing mortality rate. Weighting factors for mature and immature mortality rate were calculated on the basis of the mean averaged CPUE for specific age classes over the each of the survey series:

$$
\begin{aligned}
& \Psi_{\text {mature }, \mathrm{R}} \\
& =\frac{\sum_{J=1}^{J=P}\left(\left(Z_{a=3 \text { to } 5, J} \cdot \mathrm{CPUE}_{a=4, J} \cdot \mathrm{ssa}_{J}\right) /\left(\left(\sum_{J=1}^{j=P} \mathrm{CPUE}_{a=4, J} \cdot \mathrm{ssa}_{J}\right) / P\right)\right)}{P}
\end{aligned}
$$

$$
\begin{aligned}
& \Psi_{\text {immature } \mathrm{R}} \\
& =\frac{\sum_{J=1}^{j=P}\left(\left(Z_{a=2 \text { to } 3, J} \cdot \mathrm{CPUE}_{a=2, J} \cdot \mathrm{ssa}_{J}\right) /\left(\left(\sum_{J=1}^{j=P} \mathrm{CPUE}_{a=2, J} \cdot \mathrm{ssa}_{J}\right) / P\right)\right)}{P}
\end{aligned}
$$

where $\mathrm{ssa}_{J}$ was the sea surface area of area $J, J=1-3$ for $\mathrm{R}=$ ICES area $\mathrm{VI}$, and $J=4-10$ for $\mathrm{R}=\mathrm{ICES}$ area IV. The age groups chosen to represent mature and immature fish reflected the maturation rates in the model. In the slowest growing natal population, $45 \%$ of females were mature at age 3 , and $85 \%$ in the fastest growing population. Then, for mature fish during the spawning months of the year,

$F_{a, m, j}=\frac{Z_{a=3 \text { to } 5, J} \cdot\left(\operatorname{ICESF}_{a, \mathrm{R}}\right)_{\text {spawning }}}{\Psi_{\text {mature } \mathrm{R}}}$

where ((ICESF $\left.\left.{ }_{a, \mathrm{R}}\right)_{\text {spawning }}\right)$ represents the regional (R) age-specific fishing mortality rate during the spawning months averaged over 1980-1999 from the annual ICES stock assessment analyses. For immature fish throughout the year,

$F_{a, m, c}=\frac{Z_{a=2 \text { to } 3, J} \cdot\left(\operatorname{ICESF}_{a, \mathrm{R}}\right)}{\Psi_{\text {immature }, \mathrm{R}}}$

\subsection{Initial conditions}

Initial conditions (numbers at age on 1 January in a given year in each natal population, their distributions across nursery areas and assignments to spawning areas) were derived from a combination of trawl survey data and the annual ICES cod stock assessments for regions VI and IV (west of Scotland and North Sea respectively). The regional assessment numbers at age were distributed across the 10 model areas, in proportion to the area-specific CPUE from the trawl February/March trawl surveys. As an initial state for the model, we assumed that all the immature and mature fish in a given area were drawn from the same, local natal population.

\subsection{Output}

The mode of operation of the model was to first select one of the alternative scenarios of first-spawning migration (oceanography, homing or diffusion), repeat spawner straying enabled or disabled, and then a specific year to represent initial conditions of population age structure and abundance, regional fishing mortality rate, ocean circulation and temperature climatology. Regardless of the configuration selected, the model was then run to a stationary state with a repeating annual cycle of climatology and fishing mortality rates.

Fishing mortality rates were varied by applying a scaling factor $(\Delta F)$ to the ICES regional estimates of fishing mortality at age $\left(\operatorname{ICESF}_{a, \mathrm{R}}\right)$. Each simulation year, the programme output the total numbers of fish at age on 1 January for each natal population, and the proportions of each age class and natal population associated with each spawning and nursery area. These data were then summarised by calculating the spawning stock biomass (SSB) and recruitment for each natal population and spawning group of fish. SSB referred to males and females combined, and was calculated as the sum over each age, natal population and spawning area of the product of mature numbers at age and weight at age:

$\operatorname{SSB}_{n, y, m, j}=\sum_{a=0}^{a=20}\left(N_{\text {mature }} \times \mathrm{Wt}_{n, y, a}\right)$

Recruitment, in the context of fish population dynamics, is typically defined in terms of the surviving number of fish at a given age in each annual cohort. This concept was readily visualised for each of the natal populations in our model, but less easily so for the spawning groups because each group was composed of mature fish recruited from a dynamic mixture of natal populations. We defined recruitment in the context of a spawning group as being the number of age 1 fish on 1 January destined, should they survive, to spawn for the first time in a particular area even though they might not 
be the progeny of the spawning stock in that area. In the homing scenario, this definition of recruitment matched the number of age 1 fish in each of the natal populations. In the oceanography scenario recruitment to a spawning group was then the number of age 1 fish in the nursery area local to each spawning area. In the diffusion scenario, spawning group recruitment was the sum over all nursery areas of the age 1 fish which, if they survived, on attaining maturity would be assigned to a given spawning area, based on the emigration rate parameter and emigration pattern defined for the scenario.

\subsection{Calibration data}

We calibrated key model parameters by exploring a range of values and selecting a combination which resulted in equivalent properties of the relationship between regionally integrated SSB and recruitment simulated by the model, and that derived from the ICES regional stock assessments for cod. Of the two relevant regional stock assessments $(\mathrm{R}=$ "west of Scotland" (ICES area VI) for model areas $1-3, \mathrm{R}=$ "North Sea" (ICES area IV) for model areas 4-10), that for the North Sea has been subject to more critical review and evaluation, and was the main focus for our calibration effort. The west of Scotland assessment data are viewed as being more uncertain due to the smaller population size, poorer survey indices, less well documented catch data and less refinement of natural mortality values in the catch-at-age analysis.

The underlying relationship between SSB and recruitment is traditionally derived from a time series of fish stock demographic data by fitting a Ricker function (Ricker, 1975), or similar functional relationship, to the set of paired values of recruitment $(y)$ and SSB in the year in which the recruits were spawned $(x)$. However, a key condition of this approach is that residuals between observed and fitted recruitment at a given SSB should be random with respect to time. If this condition is not met then it is unlikely that the fitted relationship can reflect the underlying biology in a meaningful way. The most likely cause of non-randomness with respect to time would be some relationship between survival and environmental factors which vary systematically over time. In the case of North Sea cod, there is a well documented relationship between Rickerresiduals and temperature, so it was necessary for us to resolve at least this component of variability and reference the underlying SSB:recruitment relationship to the temperature regime over the period represented by our model runs.

We fitted, by Simplex optimisation, a modified Ricker model (referred to as T-Ricker) incorporating a temperature term, as described by Stocker et al. (1985), Planque and Frédou (1999), Clarke et al. (2003) and Cook and Heath (2005):

Recruitment $=b \cdot \mathrm{SSB} \mathrm{e}^{(d \cdot T-\mathrm{SSB} / f)}$

where $b, d$ and $f$ are fitting parameters.

The temperature index $(T)$ was as described by Cook and Heath (2005), i.e. the results from a factor analysis of time series of temperature at 10 locations in the North Sea, equivalent to the first component of a principal components analysis. To check for unresolved systematic time-dependent structure in residuals, we plotted log-residuals ( $\ln$ (observed recruitment) - $\ln$ (fitted recruitment)) against time (year), and fitted a Local Polynomial Regression (LOESS) smoother with a span of $0.37(n=41)$ and tricubic weighting (Cleveland et al., 1992) using the package R (R Core Development Team, 2005). Where the results showed systematic deviations from zero with time, the smoothed residuals were added back to the fitted recruitment from the $T$-Ricker function, on a year-by-year basis. Hence the pairs of observations of SSB and recruitment contained in the assessment time series could be considered as point sam-
Table 2

Spawning biomass thresholds for defining effective extinction of natal populations or spawning groups in each model area

\begin{tabular}{cc}
\hline Area & Threshold SSB (tonnes) \\
\hline 1 & 43.5 \\
2 & 99.5 \\
3 & 230.0 \\
4 & 96.0 \\
5 & 527.8 \\
6 & 112.0 \\
7 & 96.0 \\
8 & 767.7 \\
9 & 128.0 \\
10 & 799.7 \\
\hline
\end{tabular}

The thresholds were set as $1 \%$ of the maximum observed regional SSB for west of Scotland (areas 1-3) and North Sea (areas 4-10) distributed such as to assume uniform area density.

ples from a family of year-specific stock:recruitment relationships, each of which was unique depending on the prevailing temperature and other environmental condition represented by the value of time-dependent LOESS smooth. To visualise each of these yearspecific relationships, we derived recruitment values for a sequence of values of SSB in the range 0-300,000 tonnes, from the combination of year-specific temperature and the fitted $T$-Ricker equation, and year-specific values of the LOESS smoothed residuals. Statistics (median and centiles) of the underlying relationship could then be estimated over any given period of years, and these formed the basis for our calibration data for comparing with the model results.

\subsection{Characterisation of sub-stock richness and evenness}

We defined two indices to describe the richness and evenness of sub-stocks in the model, based on the Shannon-Wiener diversity index (Magurran, 1988; Sokal and Rohlf, 1995). Sub-stock richness was defined as $\ln \left(P^{*}\right)$ where $P^{*}$ was the number of extant natal populations or occupied spawning areas in the simulation. The evenness of extant populations was then given by $e^{\mathrm{SW} / P^{*}}$ where SW was the Shannon-Wiener diversity index:

$\mathrm{SW}=\sum_{J=1}^{J=P^{*}} \Theta_{J} \ln \left(\Theta_{J}\right)$ where $\Theta_{J}=\frac{\mathrm{SSB}_{J}}{\sum_{J=1}^{J=P} \mathrm{SSB}_{J}}$

High values of the evenness index corresponded to distributions which were more clumped or aggregated into a few areas, whilst low values indicated that biomass was more uniformly distributed.

We set biomass thresholds as criteria for assessing whether a natal population or spawning group was either 'collapsed' or 'effectively extinct', and hence for their inclusion in the richness and evenness indices. We arbitrarily chose $1 \%$ of the maximum observed regional SSB for the west of Scotland (37,295 tonnes) and North Sea $(252,712$ tonnes) as being appropriate regional thresholds to delineate effective extinction (i.e. 373 tonnes for west of Scotland and 2527 tonnes for the North Sea). Similarly we chose $4 \%$ of the maximum observed regional SSB as being indicative of collapse. In each case, we distributed these regional threshold SSB values across the model areas so as to assume equal area population-density over spawning areas 1-3 and 4-10 (Table 2).

\section{Results}

\subsection{Patterns in the driving data of the model}

\subsubsection{Spatial patterns of fishing mortality and abundance at age}

Average (1983-2004) values of area integrated CPUE in each model sub-area from the trawl surveys in February/March are 


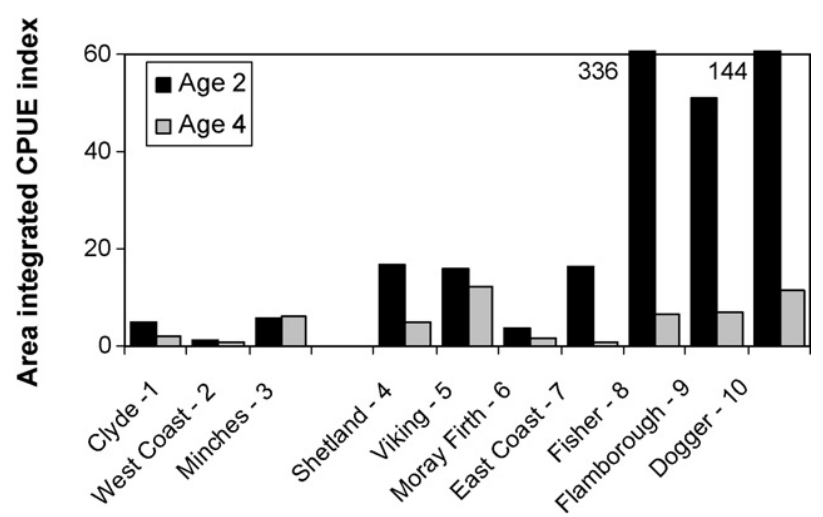

Fig. 3. Average (1985-2004) values of area-integrated CPUE in each model sub-area from the trawl surveys in February/March.

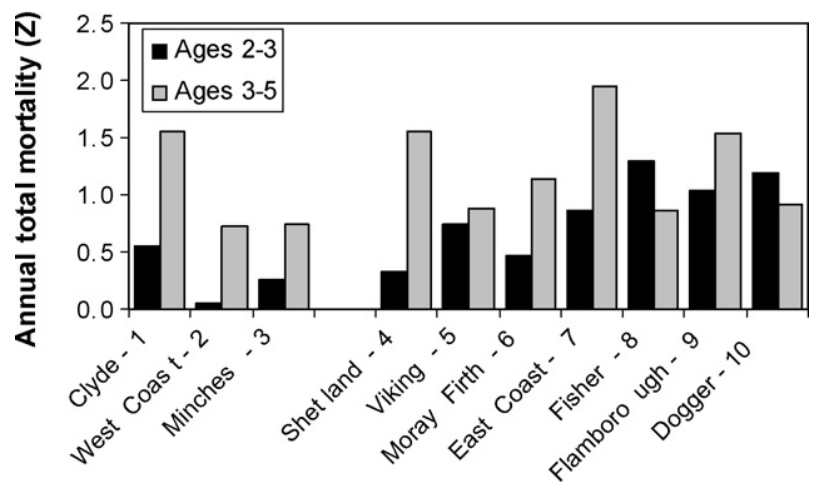

Fig. 4. Mean age-specific total mortality in each of the model areas $\left(Z_{J, a}\right)$.

shown in Fig. 3. The means of age-specific total mortality in each of the model areas $\left(Z_{J, a}\right)$ implied by these data are shown in Fig. 4. Applying these data to dis-aggregate the ICES estimates of regionally averaged fishing mortality resulted in the spawning period rates of fishing mortality, and fishing mortalities on juveniles indicated in Fig. 5.

\subsection{Straying rate of adult fish}

There were 363 records of fish having been tagged in model areas at spawning time and recaptured during spawning times in subsequent years. Of these a proportion had no associated data on the age of the fish. The Moray Firth (area 6) had the largest number of releases and recaptures, with 171 aged records of use to this study. The average proportion straying for all ages was 0.053 (Table 3 ). The $\chi^{2}=2.22$ which is $<\chi^{2}$ at $P=0.05$ of 7.815 . Therefore, the null hypothesis that there was no difference between age classes in the proportion of fish straying to other areas could not be rejected.

The standardised straying rates (proportion of tags of all ages recovered from sink areas, i.e. areas other than that in which fish

Table 3

Frequency of tag recaptures and strays outside tagging regions

\begin{tabular}{llll}
\hline Release age & Recapture age & Number of tagged fish & Strays $^{\text {a }}$ \\
\hline 1 & 2 & 24 & 0 \\
2 & 3 & 77 & 6 \\
3 & 4 & 63 & 3 \\
4 & 5 & 7 & 0 \\
\hline
\end{tabular}

a Before standardization.
Table 4

Proportion of fish tagged at spawning time in areas 1,3 and 6 which were recaptured from various areas at spawning time in subsequent years

\begin{tabular}{llll}
\hline Recapture area & \multicolumn{2}{l}{ Release area } \\
\cline { 2 - 4 } & 1 & $3^{\mathrm{a}}$ & 6 \\
\hline 1 & 0.995 & 0.030 & 0 \\
2 & 0 & 0 & 0 \\
3 & 0 & 0.894 & 0.050 \\
4 & 0 & 0.036 & 0.003 \\
5 & 0 & 0 & 0 \\
6 & 0 & 0.034 & 0.947 \\
7 & 0.005 & 0.006 & 0 \\
\hline
\end{tabular}

a Region based on standardised recoveries from two release sites.

were released) are given in Table 4. The data covered too few source areas to justify defining source specific straying rates. On the basis of the results, we assumed that the straying rate of repeat spawning fish was $5 \%$ for each source area. Sink areas were assumed to be all adjoining areas, and the strays were spread evenly across each of the sinks.

\subsection{Dispersal and survival patterns of eggs and larvae}

Averaged over all years between 1980 and 1999, a high proportion of simulated drift tracks led to sites of suitable nursery habitat from spawning locations in the southern and western North Sea (areas 6-10), and in the southern North Sea (areas 8-10) tracks were retained within the area of origin (Fig. 6). However, a lower
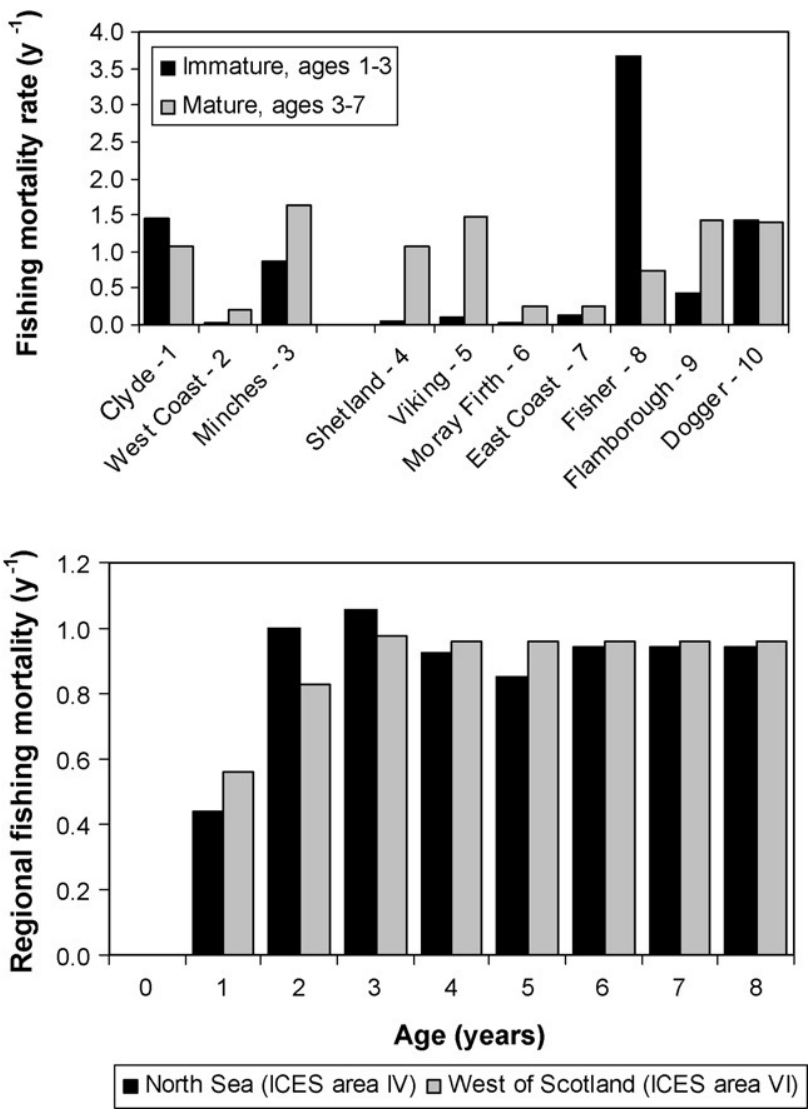

Fig. 5. Upper panel, spatially resolved fishing mortality rates on immature and mature fish, expressed as the averages over age ranges 1-3 for immature, and 3-7 for mature. Lower panel, the regional pattern of fishing mortality with age for the North Sea and West of Scotland. The mean fishing mortality rate over ages 2-6 was $0.957 \mathrm{y}^{-1}$ for the North Sea region, and $0.938 \mathrm{y}^{-1}$ for the West of Scotland. 

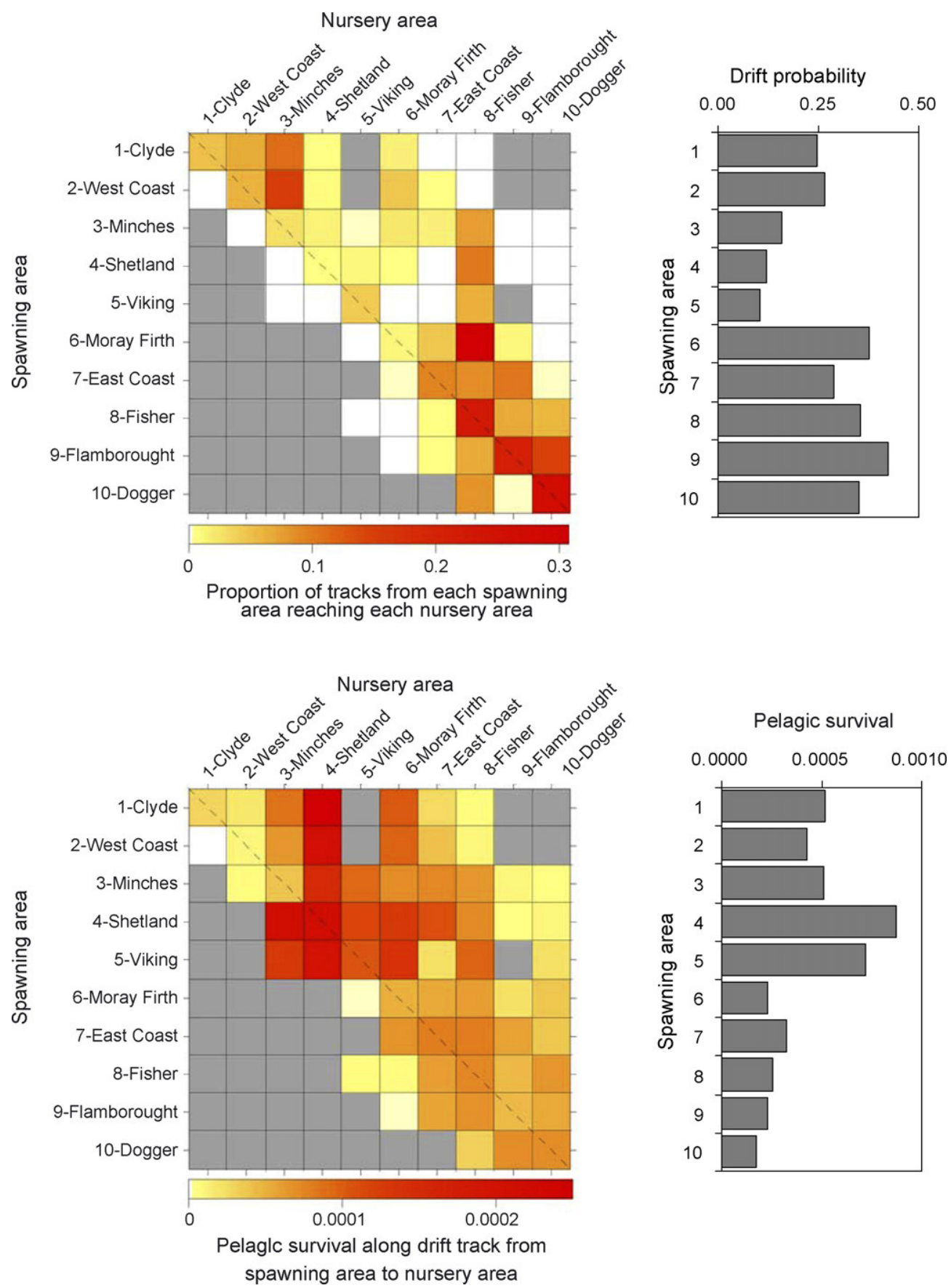

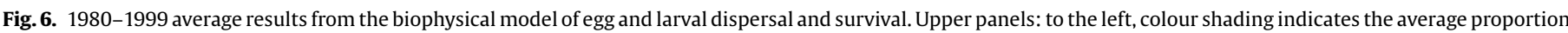

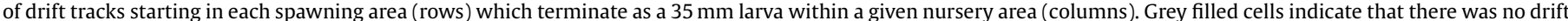

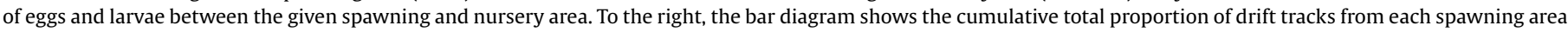

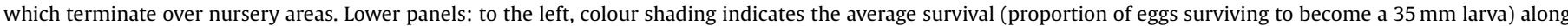

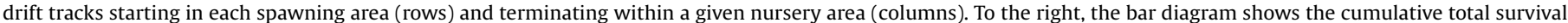
for all drift tracks from each spawning area which terminate over nursery areas.

proportion of trajectories led to nursery sites from spawning in the northern North Sea (areas 4 and 5). On the west coast of Scotland, nursery locations were more widely dispersed, and a low proportion of trajectories were retained within the area of origin.

Survival rates along trajectories that terminated over suitable nursery habitat showed a rather different pattern (Fig. 6). Tracks leading to settlement at Shetland (area 4) showed the highest survival rates, having originated from widely distributed areas of the west of Scotland and the northern North Sea (areas 1-5). Tracks ter- minating at nursery sites in the southern North Sea (areas 9 and 10) showed uniformly low survival, having originated from throughout the North Sea and north of Scotland.

Combining the drift probability and the survival rate along drift tracks, the simulations indicated that, on average and summed over all nursery areas, approximately twice as many eggs produced in the southern and western North Sea (areas 6-10) led to a surviving $35 \mathrm{~mm}$ pelagic juvenile cod located over suitable nursery habitat, compared to eggs produced off the west of Scotland and in the 


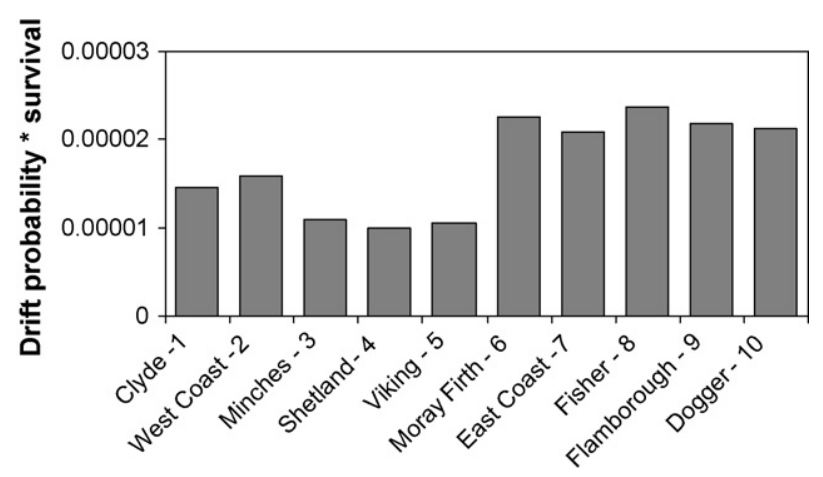

Spawning area

Fig. 7. Combined drift and survival probabilities for all tracks leading from spawning areas to nursery areas.
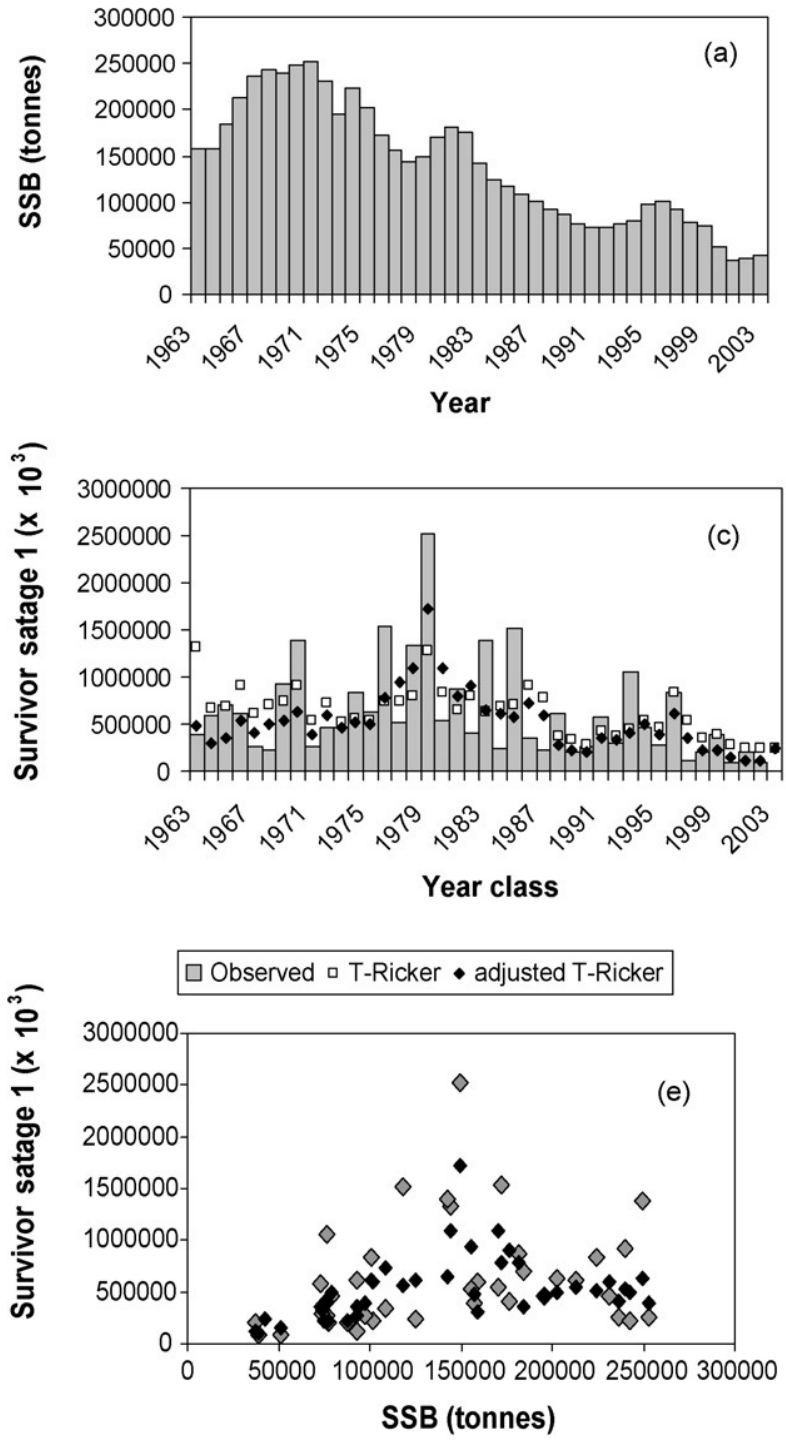

northern North Sea (areas 1-5) (Fig. 7). This proportion showed a significant $(p<0.05)$ increasing trend over time (1980-1999) for areas 8 and 10 in the southern North Sea, but no significant trend in other areas.

\subsection{North Sea regional stock:recruitment relationship}

Time series of SSB and recruitment from the ICES regional assessment of the North Sea, and the North Sea temperature index are shown in Fig. 8. Fitting of the temperature dependent Ricker model accounted for $34 \%$ of the variance in recruitment (Fig. 8). There was no relationship between residuals from the fitted model and SSB, indicating that the compensatory form of the Ricker model was appropriate for describing the observations. However, the residuals did show strong systematic time dependency (Fig. 8).
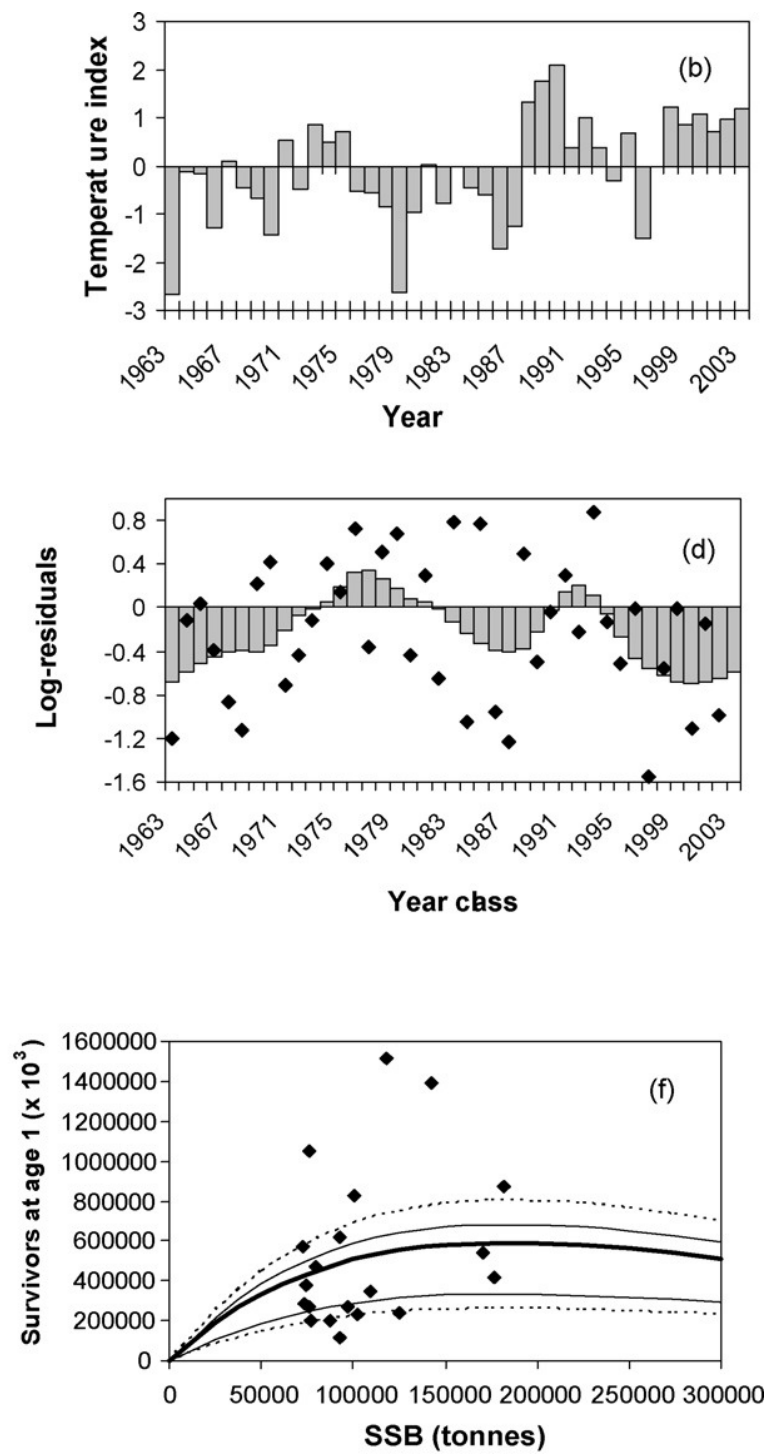

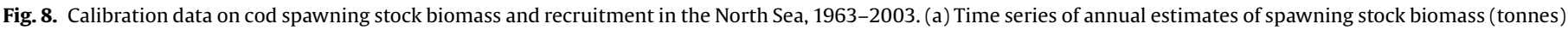

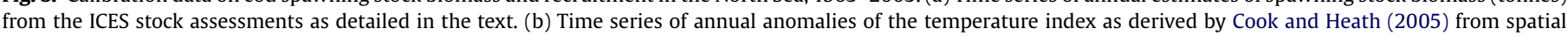

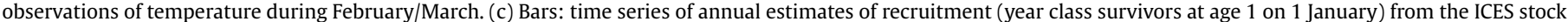

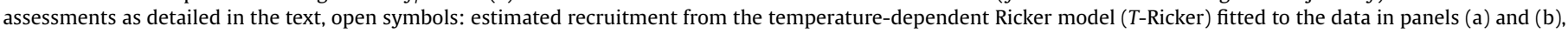

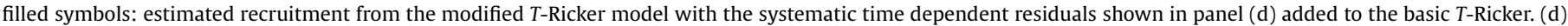

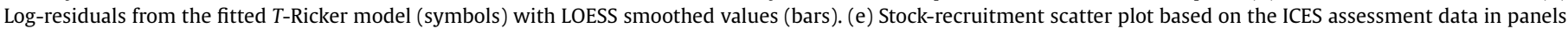

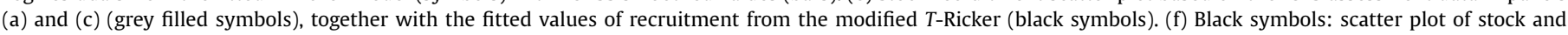

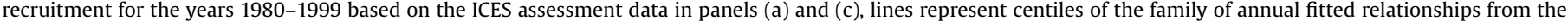
modified $T$-Ricker-thick $=$ median, thin continuous $=17$ th and $83 \mathrm{rd}$ centiles, dashed $=5$ th and 95 th centiles . 

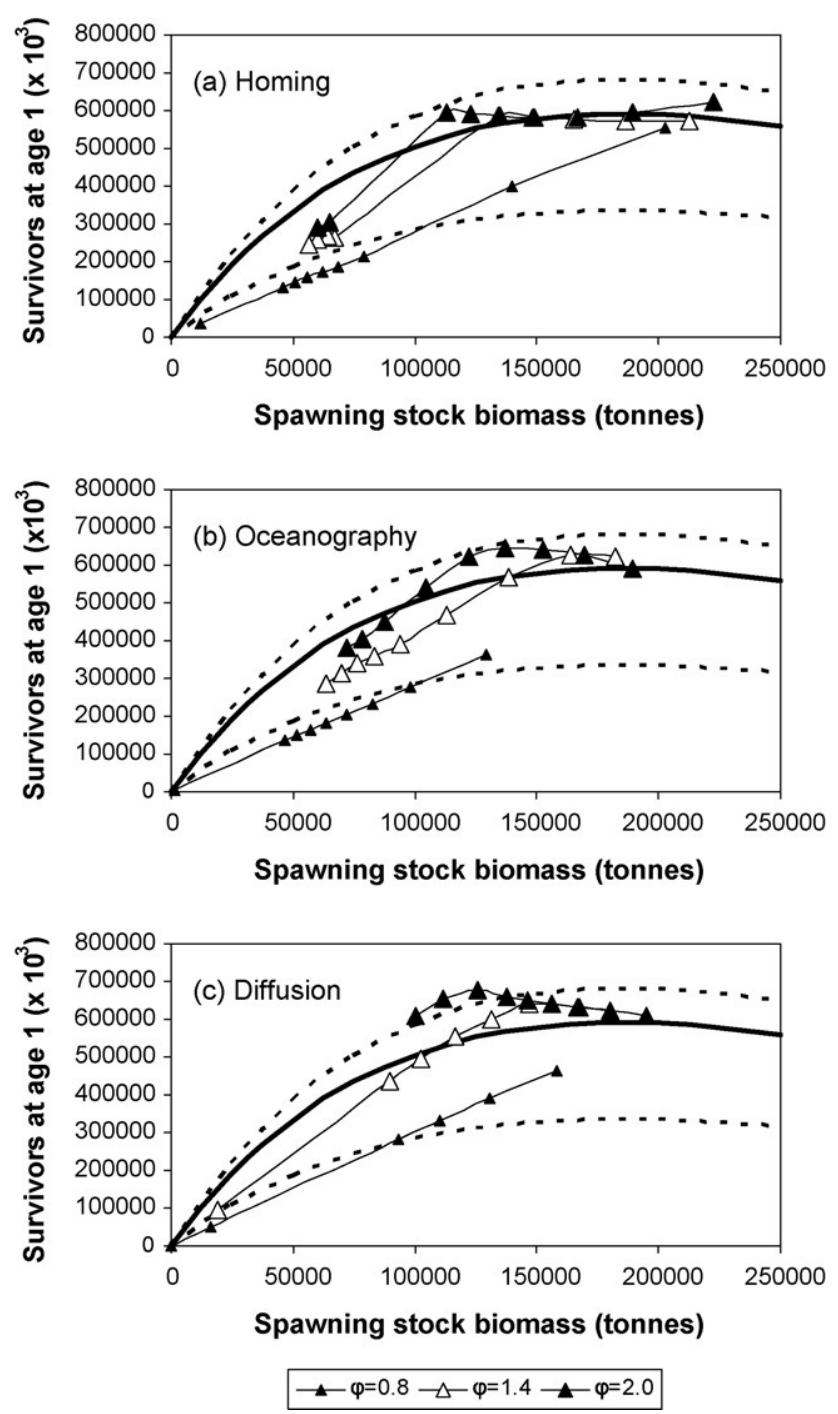

Fig. 9. Emergent relationships between equilibrium spawning biomass and recruitment, integrated over areas 4-10 (North Sea), for different values of the pelagic survival-scaling factor $\varphi$. Panels correspond to each of the three scenarios of firstspawning migration. Model data are compared to the median, 17th and 83rd centiles of the family of stock-recruitment relationships for the years 1980-1999 (from Fig. 8).

When the LOESS smooth with respect to time of these residuals was added back to the Ricker fitted values, the resulting combined estimate accounted for an increased $46 \%$ of the variance in the observations.

The median, 17th and 83rd centiles of the family of yearspecific stock:recruitment relationships over the period 1980-1999 (corresponding to the years included in the dispersal and survival estimates from the bio-physical particle-tracking model), are shown in Fig. 8. These formed the basis for calibration of the pelagic survival parameter $\varphi$ (see below).

\subsection{Model calibration and regional parameter sensitivity}

The pelagic survival estimated by the bio-physical model can only be regarded as a relative index between each combination of spawning and nursery areas. In order to estimate an appropriate value for the pelagic survival scaling factor $(\varphi)$, we simulated values of spawning biomass (SSB) and numbers of recruits (age 1 on 1 January) in each natal population, for a matrix of

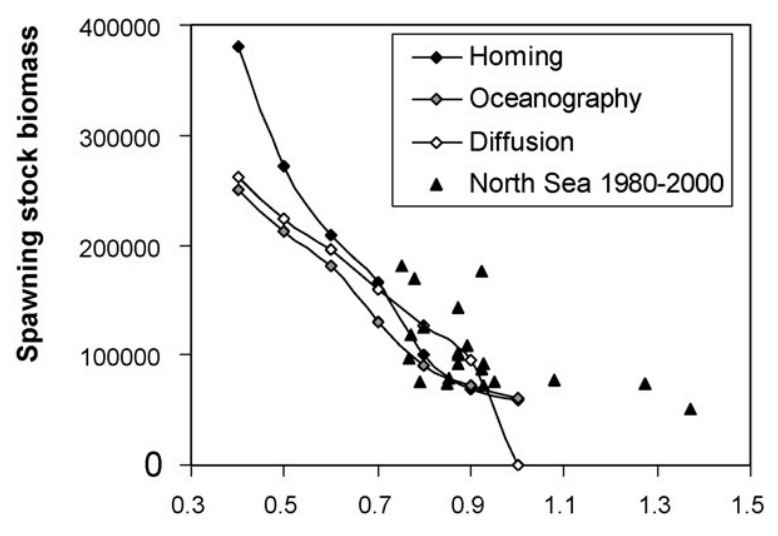

Regional fishing mortality

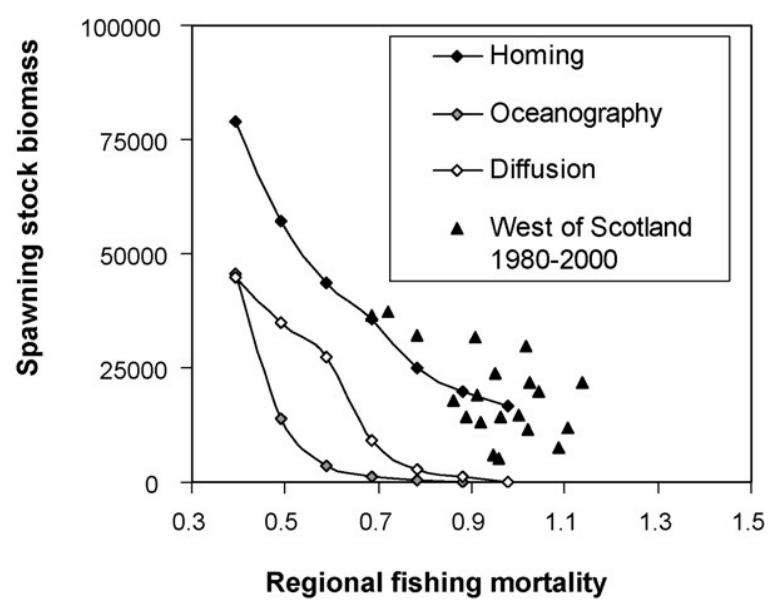

Fig. 10. Equilibrium spawning biomass (SSB) summed over spawning groups in areas 4-10 (North Sea, upper panel), and 1-3 (west of Scotland, lower panel), related to the regional rate of fishing mortality over ages 3-7 in the model. Lines represent different first-spawning migration scenarios according to the legends. Filled triangles represent the observations of SSB and age 3-7 fishing mortality rate from the corresponding ICES stock assessments.

scaling values of fishing mortality $(\Delta F)$ and values of $\varphi$. Values close to the equilibrium solution were generally obtained within 75 simulation years. For any given value of $\varphi$, the equilibrium SSB and numbers of recruits (taken as the results after 200 simulation years) were indirectly related to the fishing mortality scaling factor. Low values of $\varphi$ combined with high values of fishing mortality resulted in collapse of the entire regional population.

Based on these results, we identified by eye-fitting a value of $\varphi=1.3$ which produced an equilibrium relationship between SSB and recruitment summed over natal populations 4-10, which corresponded most closely to the slope near the origin and half-saturation properties of the median of the family of stockrecruitment relationship for 1980-1999 derived from the ICES North Sea regional stock assessment data (see above). We also chose this value of $\varphi$ as a compromise across all three of the assumed first-spawning migration scenarios. Details of shape of the simulated regional stock-recruit relationship were dependent on the assumed first-spawning migration scenario (Fig. 9). In particular the relationships emerging from the homing scenario exhibited depensatory (S-shaped) tendencies, whilst those from the diffusion scenario were clearly compensatory. 

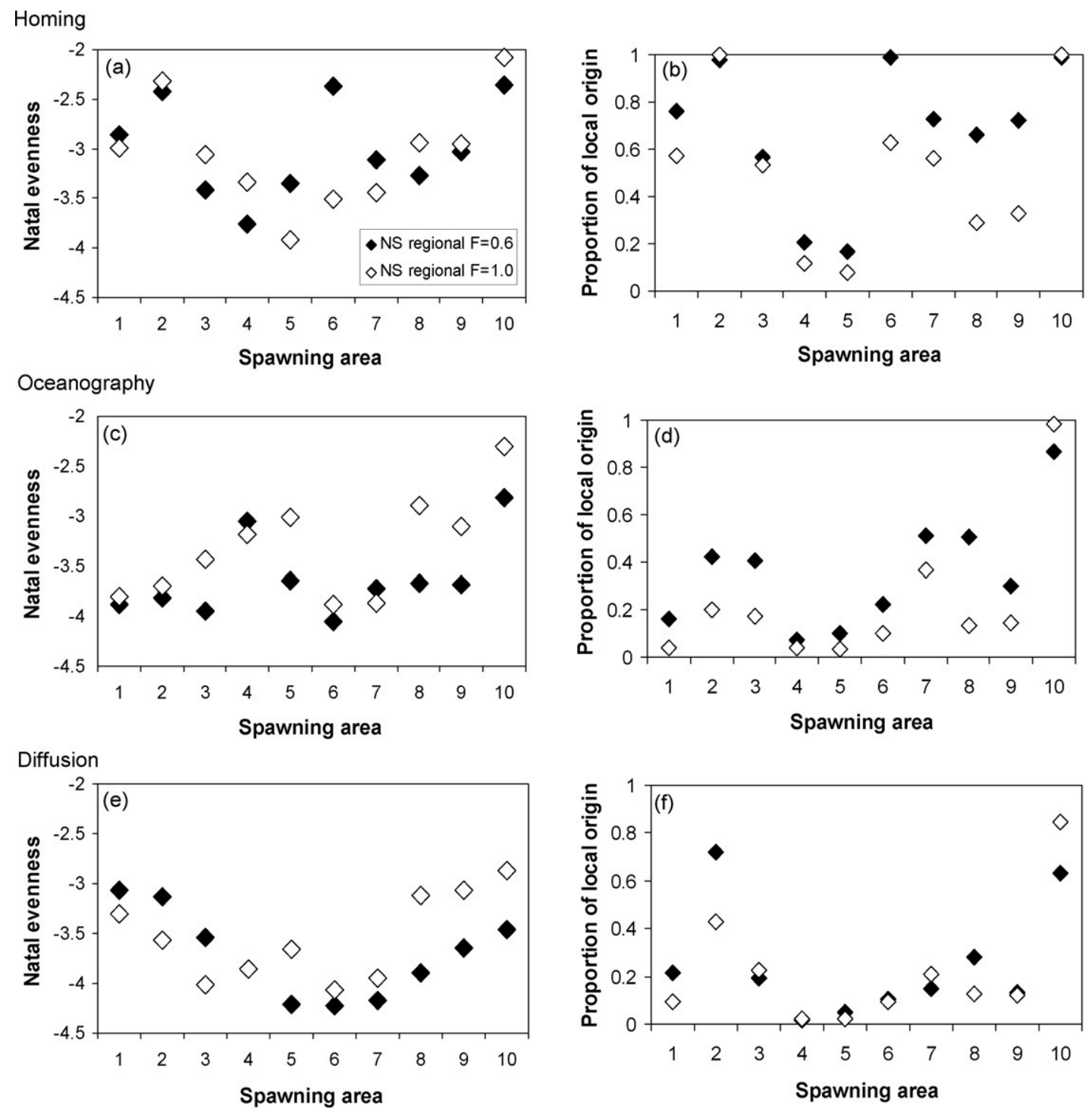

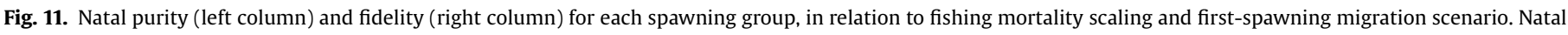

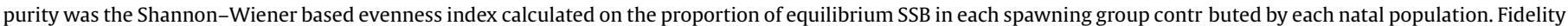
was the proportion of equilibrium SSB in each spawning group which was of local natal origin.

\subsection{Spatial sensitivity to fishing mortality and first-spawning migration scenarios}

The model predicted declining values of regional scale (summed over areas 1-3 and areas 4-10) equilibrium spawning stock biomass with increasing regional fishing mortality rate. The simulated data were compared with the observed time series of SSB and fishing mortality rate from the ICES stock assessments for the West of Scotland and the North Sea (Fig. 10), though the observed data do not necessarily reflect equilibrium conditions. In the case of the North Sea, the simulated relationship assuming the homing and oceanography scenarios of first-spawning migration conformed with the observations in that the rate of decline in SSB decreased at high rates of fishing mortality. In contrast, simulations assuming the diffusion scenario resulted in a precipitous collapse of SSB as regional fishing mortality rate exceeded 0.9. However, for the West of Scotland, only the simulations based on the homing scenario bore any relation to the observations. Both the oceanography and diffusion scenarios resulted in precipitous collapses of SSB at modest fishing mortality rates, in contrast with the observations.
The simulated natal composition of fish associated with each spawning area indicated the degree of inter-breeding between populations in the model. We estimated the degree of natal purity of each simulated spawning group by calculating the Shannon-Wiener based evenness index of the natal origins of all fish spawning in each area. High values of the index indicated a greater degree of natal purity in the origins of fish in a spawning area, and vice versa. The results (Fig. 11) indicate an overall higher degree of natal purity for spawning groups in the homing scenario than in the diffusion and oceanography cases (mean indices across all spawning groups with scaling to give a North Sea regional rate of $0.6 \mathrm{y}^{-1}$ : homing, -3.00 ; oceanography, -3.63 ; diffusion, -3.72 ). Increased fishing mortality generally increased the degree of natal purity. In the diffusion and homing scenarios, natal purity was greatest in the southern and western areas (1, 2, 9 and 10), and least in the northern North Sea (4, 5 and 6). In contrast, the oceanography scenario resulted in markedly lower purity of the western areas ( 1 and 2) whilst in the northern North Sea areas 4 and 5 showed increased purity. 

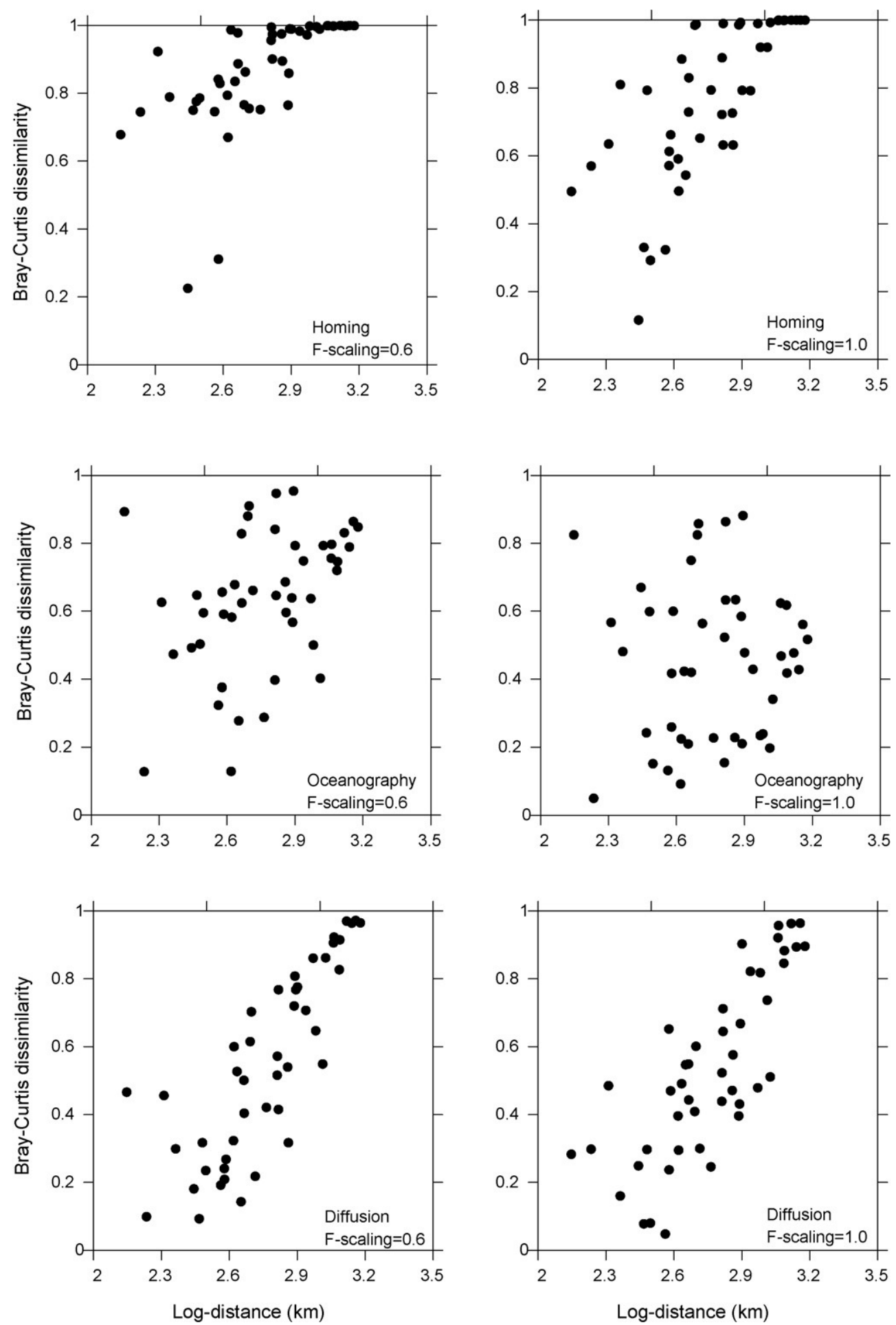

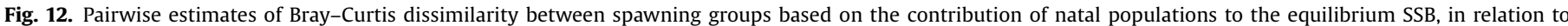

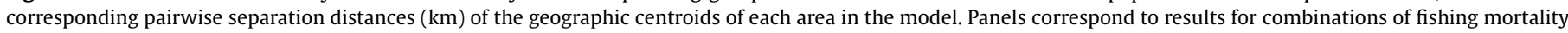
scaling factor ( 0.6 or 1.0$)$ and first-spawning migration scenario.

The scope for genetic isolation of a spawning group was indicated, not by the natal purity of spawning fish, but by the proportion of spawners which were of local natal origin (natal fidelity). The relationship between natal purity and natal fidelity in a spawning group was not straightforward. For example, in the diffusion scenario, fish spawning in area 1 had a high degree of natal purity, but only $10-20 \%$ were of local origin (Fig. 11). Most had been spawned in area 2 . Area 10 consistently showed high natal fidelity regardless of migration scenario, whilst areas 4 and 5 showed consistently low fidelity even in the homing scenario. In the homing and oceanography scenarios, natal fidelity increased with fishing mortality.

The dissimilarity between the spawning groups with respect to their natal composition was assessed by computing the matrix of the Bray-Curtis coefficient (Faith et al., 1987) for each pair of spawn- 

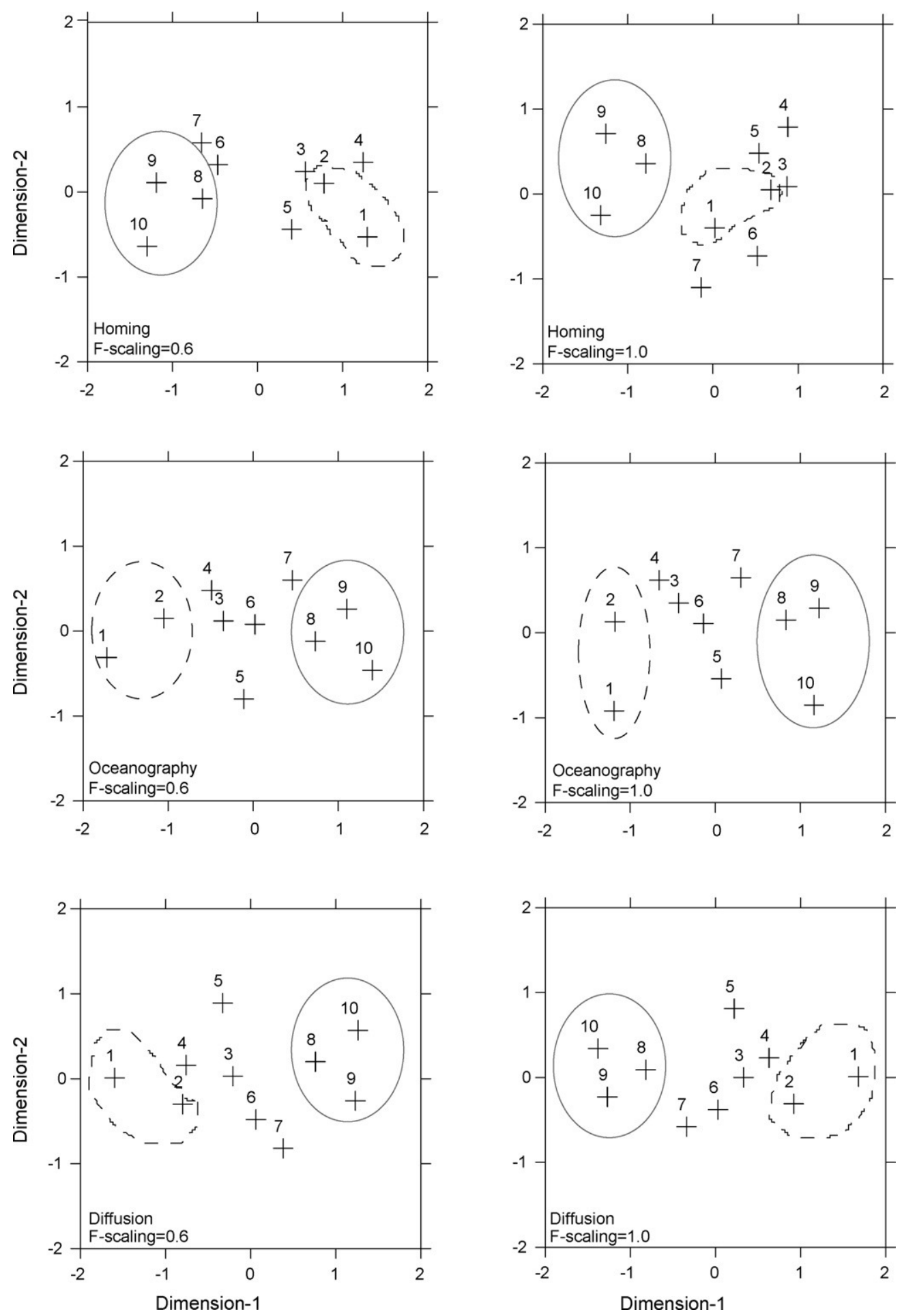

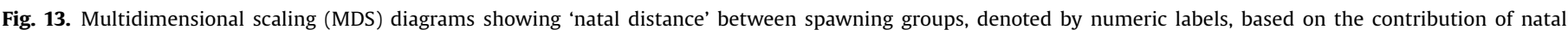

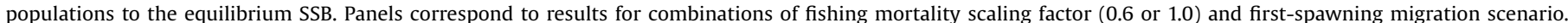

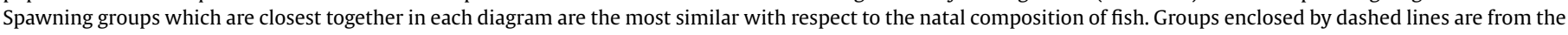
extreme southwest of the model domain (areas 1 and 2), whilst those enclosed by a continuous grey line are from the southern North Sea (areas 8,9 and 10 ).

ing groups, based on the proportions of SSB contributed by each natal population. We related the coefficients to the geographical distance $(\mathrm{km})$ between the centroids of each pair of areas. To estimate the distance between areas in the North Sea and those to the west of Scotland we used the centroids of areas 3 and 4 as 'staging posts' to compute the distance around the north of Scotland. The results (Fig. 12) showed very different patterns of spatial struc- turing based on natal composition dependent on the assumed first spawning scenario. In the case of homing, spawning groups separated by more than $1000 \mathrm{~km}$ at high $F$-scaling and $800 \mathrm{~km}$ at lower F-scaling were almost completely dissimilar. Below these thresholds, dissimilarity decreased with decreasing separation distances. In the case of the oceanography and diffusion scenarios there was no such threshold effect. With the oceanography scenario, there 

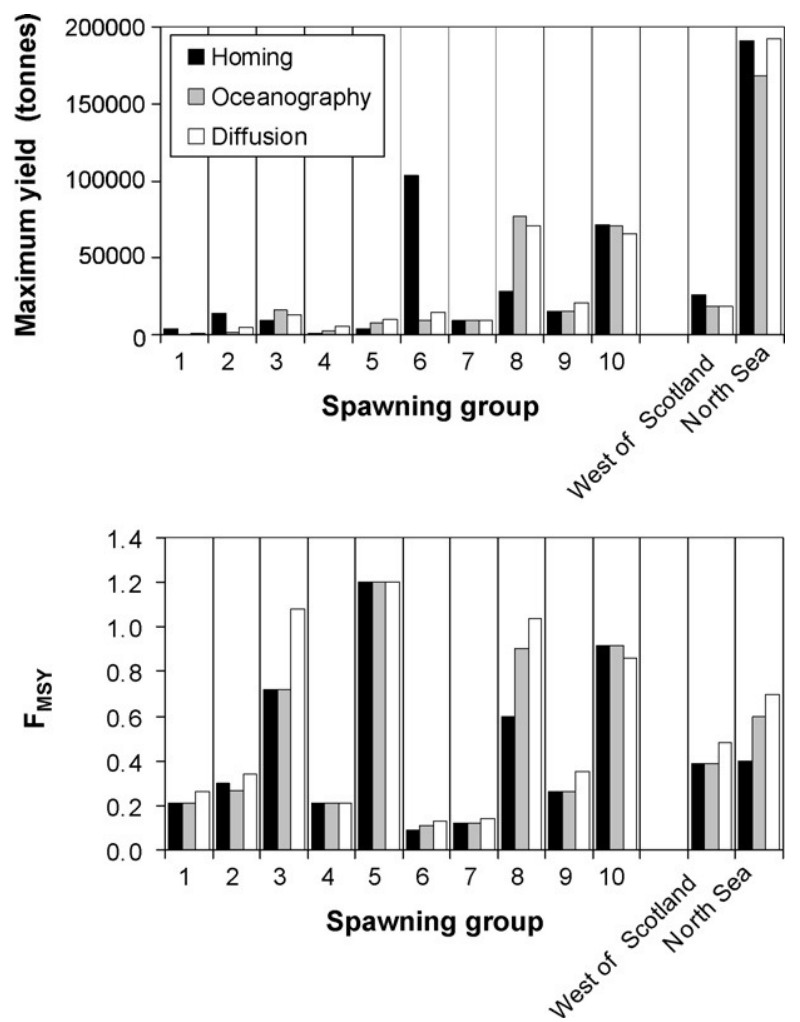

Fig. 14. Upper panel: maximum equilibrium (sustainable) yield (tonnes) for each spawning group under each of the three scenarios of first-spawning migration, together with the maximum yield for the West of Scotland region (sum over spawning groups 1-3) and the North Sea (sum over spawning groups 4-10). Lower panel: fishing mortality rate corresponding to the maximum sustainable yield ( $\left.F_{\mathrm{MSY}}\right)$ for each spawning group, and the West of Scotland and North Sea regions. For individual spawning groups the fishing mortality is the local rate for each group.

was only a weak effect of separation distance on dissimilarity at low $F$-scaling, and none at high $F$-scaling. In contrast, separation distance accounted for a high proportion of the dissimilarity between spawning groups under the diffusion scenario at both high and low F-scaling.

To investigate clustering of spawning groups with respect to natal origins, we conducted Multidimensional Scaling (MDS) analysis (Carroll and Arabie, 1980; Kruskal and Wish, 1978) with a Kruskal loss function and log-scaling of the relationship between dissimilarities and distance, based on the proportions of SSB contributed by each natal population. In each case (Fig. 13) the first dimension was closely related to the geographical structuring of the spawning areas, and hence reflected the results of the Bray-Curtis analysis. The second dimension reflected other aspects of the natal composition such as the richness and evenness, and was more sensitive to fishing mortality. Spawning groups 8, 9 and 10 emerged as being distinctly different from others in the North Sea, regardless of the assumed migration scenario and fishing mortality. In fact, increased $F$-scaling tended to accentuate the distance between these groups and the others especially under the homing and oceanography scenarios.

We extracted data from model runs with different fishing mortality scaling factors to characterise the emergent yield relationships for individual spawning groups. For each spawning group the equilibrium catch (tonnes) showed a characteristic dome shaped relationship with local fishing mortality rate, and under the oceanography and diffusion scenarios, maximum equilibrium (sustainable) yield (MSY) was greatest in areas 8 and 10 (Fisher and Dogger/Southern Bight) (Fig. 14). However, a different pattern was found when assuming the homing scenario. In this case, area 6 (Moray Firth) was estimated to produce the greatest MSY. Under all scenarios, the North Sea regional MSY (areas 4-10) was approximately 180,000 tonnes, which was in accordance with independent results from spatially integrated yield models (e.g. Cook and Heath, $2005)$. The fishing mortality rate at MSY $\left(F_{\mathrm{MSY}}\right)$ clearly varied considerably between spawning groups (areas), being $>0.5$ in areas $3,5,8$ and 10 , and $<0.2$ in the inshore areas off the east coast of the UK ( 6 and 7$)$, regardless of the assumed first-spawning migration scenario (Fig. 14). The ambient fishing mortality rates in each area derived by apportioning the 1980-1999 mean ICES regional rates across areas based on survey data (Fig. 5), were all higher than the area specific values of $F_{\mathrm{MSY}}$. For the western and northern areas (1-6), $F_{\text {ambient }} / F_{\text {MSY }}$ was between 2.0 and 2.5, whilst for the southern areas this ratio was between 1.0 and 1.6. For areas 4-10 combined (North Sea), the ratio $F_{\text {ambient }} / F_{\text {MSY }}$ was $>2.0$ when assuming homing, and in the range 1.3-1.6 assuming the oceanography or diffusion scenario.

\subsection{Recovery scenario analysis}

We conducted a scenario analysis of recovery from a collapsed state. Area specific fishing mortalities were scaled such that the North Sea regional rate was $1.0 \mathrm{y}^{-1}$, and the model then run until half of the spawning groups had declined to less than the threshold for collapse (4\% of the maximum observed regional SSB apportioned across spawning areas). Fishing mortality rates were then rescaled so that the North Sea regional rate was $0.5 \mathrm{y}^{-1}$ and the run continued.

The time from the start of each run until 50\% of the spawning groups had collapsed varied depending on the assumed firstspawning migration scenario (homing, 29 years; oceanography, 30 years; diffusion, 20 years). Following relaxation of the fishing mortality stock richness was restored to the equilibrium for the post-relaxation mortality scaling within 20 years for the homing and diffusion scenarios, but only by 45 years for the oceanography scenario (Fig. 15). Conversely, overall spawning stock biomass re-attained equilibrium more quickly assuming the oceanography scenario (within 20 years) than with the homing or diffusion scenarios (up to 50 years). This pattern was also reflected in the individual spawning groups, which showed very different transient patterns of SSB following relaxation of fishing mortality.

\section{Discussion}

\subsection{Spatial modelling of population dynamics}

Spatial modelling of physiologically structured populations is a well-known source of numerical difficulty (McKendrick, 1926; von Foerster, 1959). A number of numerical implementations are available to represent the development of homogeneous populations comprising distinct age-based developmental stages (e.g. Gopalsamy, 1997; Mollison, 1991; Van den Bosch et al., 1990; Diekmann et al., 1998; Gurney and Nisbet, 1998; de Roos, 1997). Most fish stock models currently in operational use for European waters are of this type. However, none of these can readily accommodate space dependent development. This is because cohorts will have different development histories at different locations in space, and the average which results from advective or diffusive mixing does not represent the state of all of the constituents.

Alternative modelling approaches require that the life history be divided into discrete stages based on size or some other measure, with the transition between stages being defined by a probability distribution. By assuming that all individuals within a stage are indistinguishable, the scheme can be expanded to accommodate 


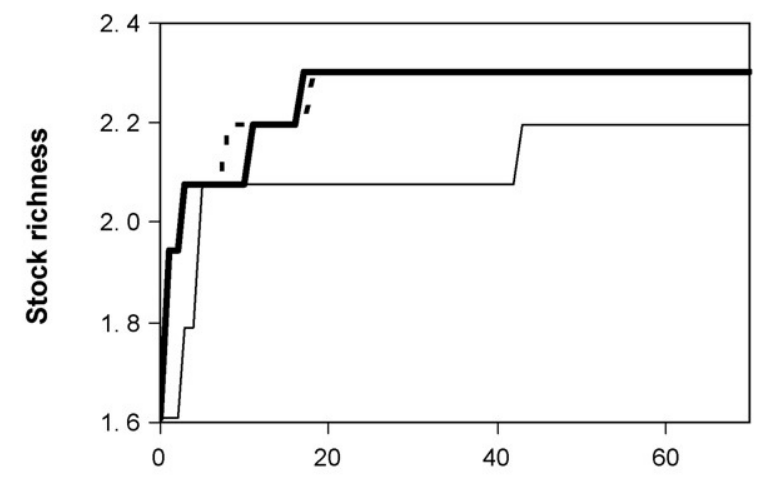

Years from relaxation of $F$

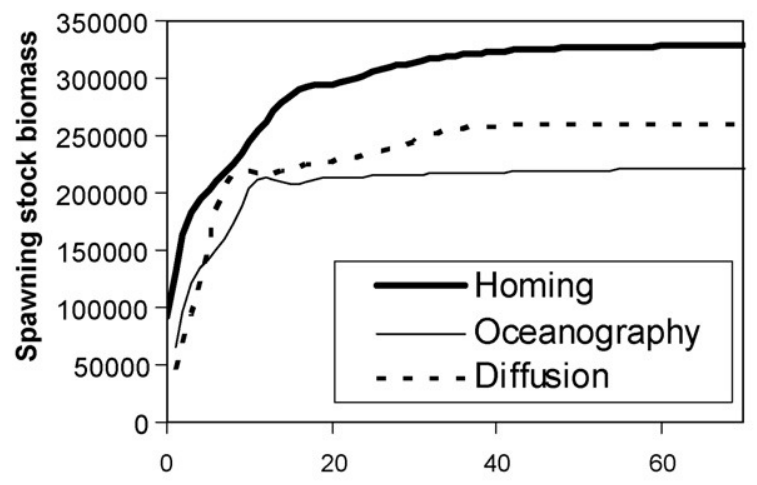

Years from relaxation of $F$
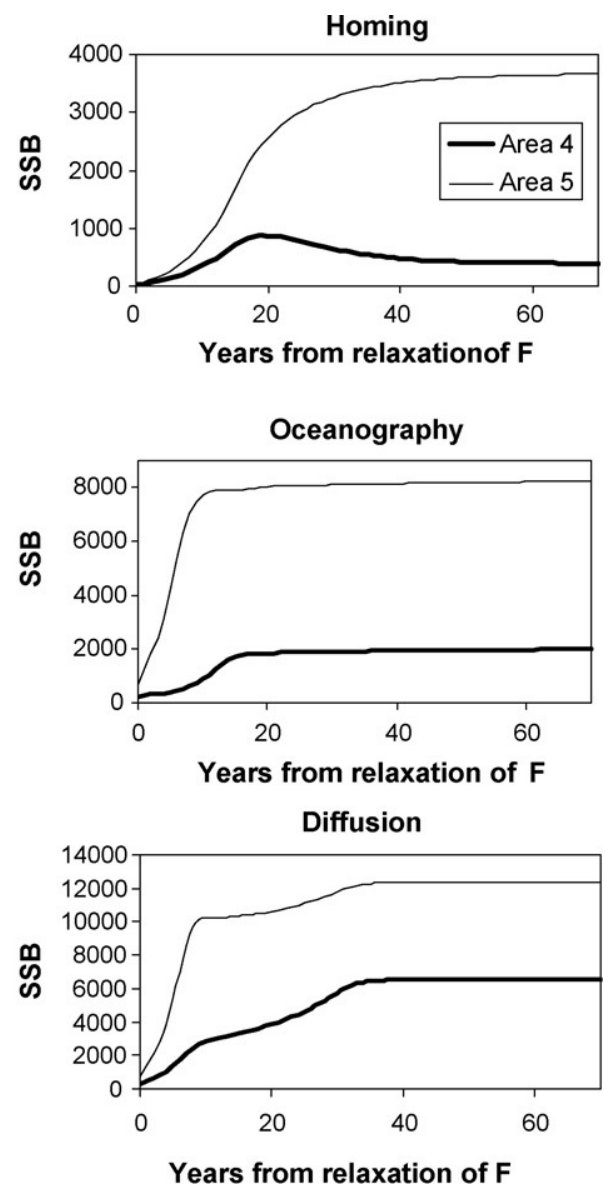

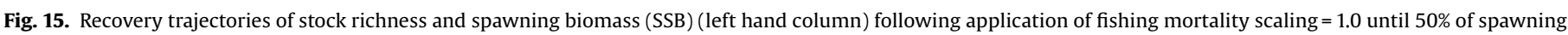

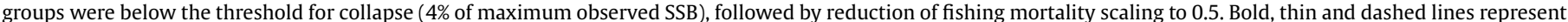

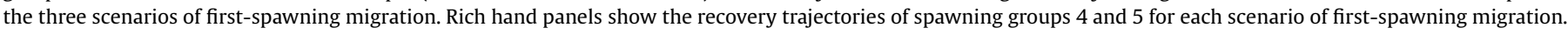

spatial structure (Neubert and Caswell, 2000). Examples of the use of this method for planktonic taxa are Bryant et al.(1997), and Gupta et al. (1994). However, the weakness of the Neubert and Caswell approach is that each development class is considered to be homogeneous. This means that with a uniform time step for updating the population, the distribution of stage durations is highly sensitive to the number of stages. Various methods are available for more or less controlling the numerical diffusion which increases as the number of stages is decreased. For fish, where body size ranges over many orders of magnitude over the life cycle, this is a serious problem.

Gurney et al. (2001) developed a different approach to resolve these difficulties. Update intervals for development classes were independent of transport, such that in each spatial grid cell all the members of a development class were transferred to the next class at the same time. Hence the update interval for development will vary in space and time, but numerical diffusion is eliminated. Spatial dispersal by migration, advection and diffusion are updated independently by reference to a redistribution matrix which defines the proportion of individuals from each location which are to be transferred to all other locations. The scheme works best when spatial dispersal updates are widely spaced in time compared to the slowest developmental updates. Gurney et al. (2001) illustrated the method by developing a population model of Calanus finmarchicus in the northeastern Atlantic. The spatial redistribution matrix was determined by an external particle-tracking model. Comparisons between the new Eulerian grid method and a Lagrangian based approach showed high conformity across a range of grid scales.
The Gurney et al. method was used by Andrews et al. (2006) to develop a spatially resolved population dynamics model of cod in European waters. The model represented a biologically homogeneous population of cod throughout the model domain, combining spatially resolved mortality, growth and reproduction with larval drift, and migrations by juvenile and adult fish. The spatial scheme had a resolution of approximately $60 \mathrm{~km}$ over the shelf region extending from Brittany in the south to the northern limit of the North Sea. Andrews et al. fitted various structural alternatives of the model, representing different hypotheses about migration behaviour, to spatial and temporal data on cod abundance and then used the fitted parameterisation to explore the consequences of various spatial measures applied to fishing mortality. However, whilst the model was capable of simulating spatial dynamics which compared favourably with observations, the results cannot be used to make any inferences about the degree of natal fidelity. To do this would require a significant increase in complexity, by resolving a set of separate genetic populations or demes and their potential interactions, each of which would have to be simulated in parallel.

Resolution of discrete demes was a key objective of our modelling effort. To achieve this, we compromised on the spatial resolution, representation of mixing, and spatial dependency of development rates achieved by Andrews et al. (2006). The key simplifying assumption we made was that all individuals in a given deme are endowed at birth with the same future growth trajectory, which they follow regardless of where they eventually live in the model domain. This allowed us to employ an age-based, discrete time methodology for simulating the population dynamics, 
without the penalties associated with most spatial versions of such types of model.

Endowing fish with a future growth trajectory at birth, results in a number of simulated outcomes that mimic properties of fish populations which we observe in the field. For example, spawning groups comprising fish of a variety of natal origins will exhibit a range of lengths at age within the group. In other species (herring), variation in length at age within a group of mature fish has been related to nursery area origin using parasite fauna (Heath and Baird, 1983). Clearly, nursery area origin is not necessarily the same as natal origin, but the particle tracking simulations described in this paper indicate that there is a loose connection between the two. Our assumption regarding growth trajectories could therefore be summarised as being that most fish in each natal population follow a similar trajectory through the environment over the course of their life, and hence we assume that the development rates of the majority are applicable to all in the population. In addition, recent evidence indicates that cod from different sub-regions of the North Sea and west of Scotland do have inherently different developmental schedules under exposure to equivalent thermal environmental conditions (Perutz, 2007). Yoneda and Wright (2004) showed that reproductive investment of inshore cod from the northern North Sea has diverged significantly from that of cod from offshore groups over a 30 -year period. The authors noted that the difference was consistent with pheno- and genotypic selection arising from intense size selective fishing mortality predicted by life-history theory (Rochet, 1998; Rochet et al., 2000; Jørgensen et al., 2007). There are also precedents for such an assumption amongst other vertebrates, for example, the adult survival rate of red billed choughs on the island of Islay has been shown to be more related to natal region than to subsequent settlement and breeding region, implying either a genetic basis for survival differences between natal groups, or a degree of conditioning by early life environment (Reid et al., 2006).

\subsection{Key factors affecting population structure and dynamics, and identifying gaps in knowledge}

Our model contains a number of uncertain parameters (see Appendix A), but the key structural variable affecting both the regional and sub-area level dynamics was the assumed firstspawning migration pattern of fish. Unfortunately, knowledge of this behaviour in the field is almost completely absent since artificial tagging of larval and juvenile fish is not practicable, and even if this was possible, mortality rates are such that the subsequent return rate from commercial fisheries would be extremely low. Hence, we speculated as to possible behaviours and compared these as structural alternatives of the model. Our homing and oceanography scenarios represent opposite extremes of the possible range of behaviours, which in reality are not necessarily mutually exclusive. In the homing scenario, fish were assumed to navigate back to their natal spawning ground from wherever they may have settled and grown up as juveniles, in much the same way as Atlantic salmon return from the ocean to their natal river or even tributary to spawn (Valiente et al., 2005; Verspoor et al., 2002). There was no such navigation behaviour in the oceanography scenario, and newly matured fish simply spawned in the area local to where they had spent their juvenile years. Hence, in the oceanography scenario, the natal composition of first spawning fish in the spawning groups was entirely dictated by the dispersal and survival patterns of eggs and larvae by water currents.

Otolith elemental composition analysis of juvenile cod from around the northern UK has shown that juveniles from different nursery areas are readily distinguishable by their isotopic composition (Gibb et al., 2007; Wright et al., 2006b). Moreover, the majority of older fish at the sites examined (Clyde, Shetland, Minch, Inner
Hebrides) were found to have isotopic signatures similar to those of locally caught juveniles, and the results implied that $>90 \%$ of adults at each location had originated from the local nurseries rather than distant groups of juveniles (Wright et al., 2006b). If natal homing is a general property of cod, then the results imply that the sampled juveniles were predominantly of local natal origin. In the case of the Clyde, particle tracking and oceanographic evidence suggest that a high proportion of juveniles should indeed be of local natal origin, so the elemental composition results could arise through either natal homing or behaviour such as our oceanography scenario of first-spawning migration. In contrast, the particle tracking evidence for Shetland suggests that there is a high probability of immigration by larvae from distant sources, and export of locally produced eggs and larvae to a range of other nursery areas. If this is the case, the elemental composition data from Shetland would appear to rule out natal homing. However, as a note of caution, modelling currents around the Shetland Islands is particularly challenging due to the complex topography, and the spatial resolution of the hydrodynamic flow-fields used for this study ( $14 \mathrm{~km}$ grid spacing), whilst adequate for open shelf regions, could not have resolved smaller scale inshore circulation features which might lead to a degree of local retention of eggs and larvae. Perhaps cod show different degrees of natal homing in different regions, or under different circumstances. There is clear evidence of homing elsewhere in the North Sea, since Svedäng and Svenson (2006) and Svedäng et al. (2007) have presented genetic and tagging evidence that juvenile cod in the Skagerrak and Kattegat originate from both local and distant North Sea spawning grounds, but on maturation the fish of North Sea genotype leave the area and apparently migrate to spawning sites in the North Sea, whilst the fish of local genotype remain.

In contrast to the vagueness of our understanding of firstspawning migrations, there is considerably more documentation of spawning area fidelity by repeat spawners (Robichaud and Rose, 2001, 2004; Wright et al., 2006a). We were able to use tag return data to parameterise the repeat spawner straying rate in our model with some confidence. Although the data were not gathered from the whole domain of our model, the results are consistent with those reported from, for example, the southern North Sea (Metcalfe et al., 2005), and more recent data on the residency of coastal cod around the north of Scotland (Neat et al., 2006). In the absence of repeat spawner straying, model runs with the homing scenario for first time spawners would function as an independent set of populations, except to the extent that they might compete at settlement from the pelagic to the demersal phase. The introduction of $5 \%$ repeat spawner straying clearly had marked dynamic consequences for the system, and resulted in significant deviations from natal purity. An interaction of repeat spawner straying and fishing was also evident in the homing scenario runs, with natal purity and fidelity being degraded at higher fishing mortality rates.

One of the primary purposes of our study was to provide a modelling framework for evaluating the results from molecular genetics studies of cod stocks in European waters. Hence, we adopted a deme-based structure in which we could track the natal origin of fish spawning at each location in the model. Each natal population in our model represented a homogeneous group of fish with respect to origin, and under a homing scenario with sufficiently small straying rates these could be expected to be genetically distinct. Hence, by analysing the natal composition of fish in each spawning group we could draw inferences on likely genetic structures. Based on a correlation between pairwise measurements of genetic distance from microsatellite DNA analysis and geographical separation of samples, Hutchinson et al. (2001) concluded that isolation by distance was a significant factor in the genetic structuring of cod, not only on the macrogeographic scale (i.e. comparing European cod 


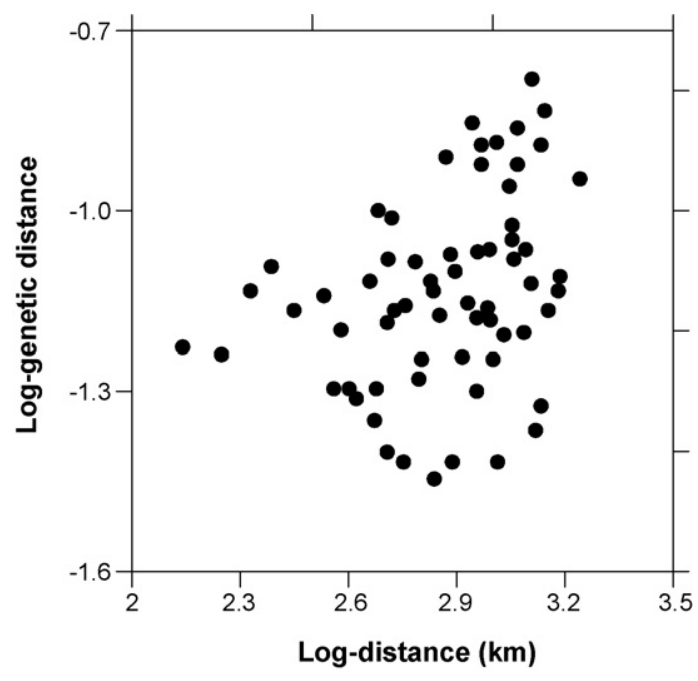

Fig. 16. Redrawn from Fig. 2 of Hutchinson et al. (2001). Pairwise comparisons of geographical separation distance $(\mathrm{km})$ of cod samples collected in European waters, and their corresponding genetic distance $\left(D_{\mathrm{s}}\right)$.

with Norwegian and Canadian specimens), but also on the European scale. The authors identified four spawning groups of cod in the North Sea which appeared genetically distinct: Bergen Bank, Moray Firth, Flamborough and Southern Bight, with the Southern Bight fish being the most genetically distant from others in the North Sea.

Comparison of the genetic distance data of Hutchinson et al. (2001) (Fig. 16) with the patterns of natal distance which emerged from our model results (Fig. 12) suggests little support for the homing scenario of first-spawning migrations. The characteristic feature of homing is a threshold separation distance of approximately $1000 \mathrm{~km}$ above which pairwise comparisons of natal composition show almost complete dissimilarity. This feature is clearly absent from the genetic data which show the strongest resemblance to the pattern which emerged from the oceanography scenario (correlation coefficient $(r)$ between genetic distance and geographical separation, 0.33; correlations between Bray-Curtis natal dissimilarity and geographical separation (with model $F$-scaling=0.6): homing, 0.63; oceanography, 0.40; diffusion, 0.81).

The genetically distinct groups of fish identified by Hutchinson et al. (2001) correspond to fish spawning in areas 5, 6, 9 and 10 in our model. None of our first-spawning migration scenario runs identified spawning fish in areas 5 or 9 as being of pure or natal origin. Area 6 (Moray Firth) emerged as having the potential for genetic isolation only in the homing scenario. However fish spawning in area 10 consistently emerged as being of high natal purity and local natal origin regardless of migration scenario, principally by virtue of the high retention of pelagic juvenile stages within the area. Hence our model provides support and explanation for the genetic evidence of a sub-stock of cod in the Southern Bight of the North Sea which is sufficiently isolated by distance and oceanography to lead to genetic isolation.

Overall, it was difficult to distinguish one of the structural versions of the model (i.e. different first-spawning migration scenarios) as providing a superior account of the observed spatial demography. Indeed, the results indicate that the scenarios may not be mutually exclusive, such that behaviours in different regions may be best described by different degrees of homing, oceanography or diffusion. Integrated to the regional scale, the homing scenario produced results which were most consistent with the observations of SSB in relation to fishing mortality for both the North Sea and the West of Scotland. However, at the individual

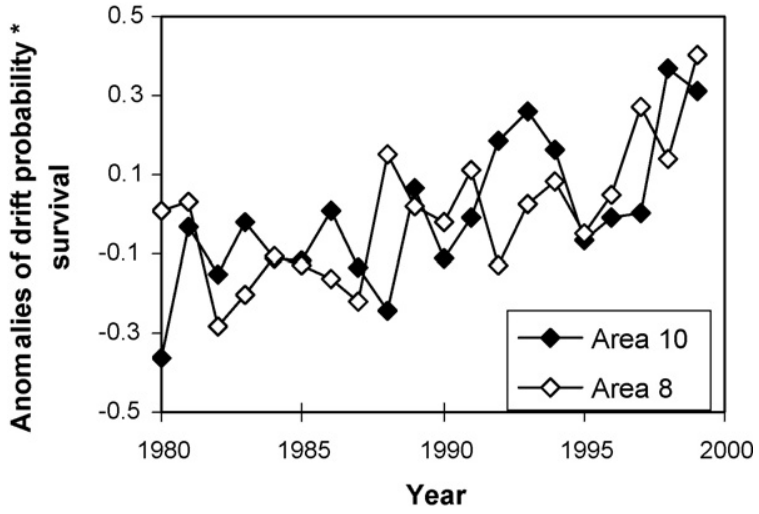

Fig. 17. Annual anomalies (proportion of 1980-1999 mean) of combined drift and survival probabilities for cod eggs spawned in areas 8 and 10 retained within their natal area (1980-1999), simulated by the bio-physical particle-tracking model.

spawning group scale, this scenario was the least successful at simulating the distribution of biomass. The diffusion scenario was outstandingly poor at representing the regional scale response of SSB to fishing mortality in both the North Sea and the West of Scotland, predicting regional collapse at only modest levels of mortality. The oceanography scenario provided the better account of spatial distribution at the spawning group level, but spectacularly failed to represent the relationship between SSB and fishing mortality at the regional scale for the West of Scotland. We speculate that this is because we have restricted the south-western boundary of our model to exclude the Irish Sea/Celtic Sea and west of Ireland where there are known to be significant populations of cod. In the oceanography scenario the mean circulation around the UK would imply that, e.g. the Irish Sea should be a significant source area of juveniles settling in our model areas 1, 2 and 3. In the absence of these sources in the model, the west of Scotland populations were only sustainable by invoking an active return migration to generate recruitment. In summary, we can conclude that homing is not a necessary behaviour in order to sustain some of the major population structures detectable in the field, in particular the relative isolation of the southern North Sea. But, the available evidence from genetic, tagging, otolith elemental analysis, and our model results, indicates the existence of migration behaviours ranging from the oceanography scenario to homing in different spawning groups, and the rules which dictate what actually happens in individual cases remain elusive.

\subsection{Climate variability}

If oceanography alone is capable of generating sub-population structure in European cod, then conversely we should conclude that structure must be sensitive to oceanographic variability. Our results from the particle-tracking model showed inter-annual variability, but no significant underlying trends in the overall probability of spawning products for any area being located over any patch of nursery habitat at the appropriate time for settlement. However, for areas 8 and 10, there was significant $(p<0.05)$ increasing trend in the overall product of drift and survival probabilities. More particularly, the proportion of spawning products surviving to settle in the same area that they were spawned showed a strongly increasing trend for areas 8 and 10 (Fig. 17). Hence, climate changes have resulted in a trend of increasing natal retention in the southern North Sea, which should result in enhancement of the genetic distance between these areas and the rest of the model domain. 
The conclusion that spawning products from the southern North Sea have been increasingly retained in their natal area over the years since 1980, is diametrically opposite to that of Rindorf and Lewy (2006). These authors found a significant correlation between northwards directed wind stress, temperature and the latitudinal location of the centre of mass of juvenile cod in the North Sea, but not with mature cod. In years with mild windy conditions in winter, the centre of mass of the corresponding year class of demersal juveniles was located further north. It appeared that once established for a year class the latitudinal location was maintained throughout its life due to the low straying rate of established spawners-a hypothesis mimicking the oceanography scenario in our model. Since mild, southwesterly wind conditions have been increasingly prevalent in winter and spring months since 1980, the authors concluded that the progressive northwards displacement of cod abundance in the North Sea since 1980 (see also Perry et al., 2005) was due primarily to early life stage dispersal and survival processes, and that there was no evidence to suggest that mature cod had migrated northwards to evade elevated sea temperatures in the southern North Sea. However, the authors presented no evidence from circulation modelling to support their contention that southerly wind stress resulted in more northerly dispersal of eggs and larvae from the southern North Sea.

Rindorf and Lewy (2006) found no relationship between North Sea regional fishing mortality rates and the latitudinal location of cod, but acknowledged that this was not a robust test of an alternative hypothesis that spatial patterns of fishing mortality have contributed to changes in latitudinal distribution. As we indicate here, data that may be used to establish spatial distributions of fishing mortality rates in the North Sea are very hard to obtain, and the data needed to convincingly describe space and time variability are apparently not available. However, it is clear from our model results that such a hypothesis has potential as an explanation of the observations. In addition, we should be able to predict changes in the natal composition of cod in different spawning areas which would be diagnostic of a fishing mortality hypothesis as opposed to an early life stage dispersal hypothesis. This aspect is one of our future plans for use of the model.

\subsection{Implications for management of cod stocks}

It is clear from tagging and otolith elemental analyses that cod in the North Sea do not constitute a homogeneous population that will freely redistribute in response to local variability in exploitation. Hence, local exploitation has the potential to deplete local populations, perhaps to the extent that depensation occurs and recovery is impossible without recolonisation from other areas, with consequent loss of genetic diversity. Our simulated yield curves for each individual spawning group suggest that estimates of 1980-1999 local rates ( $F_{\text {ambient }}$ ) derived by apportioning the ICES regional values according to survey data are higher than the local fishing mortality rates at maximum sustainable local yield $\left(F_{\mathrm{MSY}}\right)$. There was apparently a geographical structure to the ratio $F_{\text {ambient }} / \mathrm{F}_{\mathrm{MSY}}$, implying that western and northern spawning groups were being exploited more in excess of $F_{M S Y}$ than southern and central North Sea groups.

Our simulations suggest that recolonisation of extinct spawning groups is feasible, given the processes represented in the model. A note of caution should be that background rates of natural (non-fishing) age-specific mortality are assumed to vary only as a reaction to high abundances, acting as a compensatory mechanism limiting the maximum population size. Because we have no evidence of their operation in European waters, we have not included any representation of possible depensatory variations in mortality rate, acting at low abundances, which could inhibit recovery at low population sizes (Frank and Brickman, 2000). Nevertheless, the simulations described here indicate that strategies for spatial management of fishing activity do not necessarily have intuitive outcomes, since the consequences of manipulating local fishing mortality can be realised elsewhere in the system depending on connectivity and migration patterns. Key to the process of recolonisation and rebuilding is the intrinsic growth rate of local populations which, in the absence of fishing, is governed by natural mortality and recruitment. But, under our oceanography representation of first-spawning migrations some areas are sustained by only a small proportion of local natal recruitment, the majority being immigrants from other areas due to passive transport processes. Thus, whilst our equilibrium simulations imply that each spawning group has a defined stock-recruitment relationship, this is merely a reflection of the equilibrium egg production in surrounding source areas of recruits. Hence, to promote recovery of a depleted population, the key factor is to identify the spawning areas which act as the main source of settling pelagic juveniles and act to promote these, as well as limit fishing in the target area.

\section{Acknowledgements}

This work was co-funded by EU-METACOD project (EU FP6 QLRT-2000-00953), and the Scottish Government.

\section{Appendix A. Formulation and parameterisation of biological processes}

\section{A.1. Development}

For each natal population, we defined a von Bertalanffy growth in length $\left(L_{n, y, m, a}\right)$ trajectory over time from hatching, which was retained throughout life, regardless of subsequent spawning affiliations. We adopt the parameters of Andrews et al. (2006). These authors first fitted a von Bertalanffy function:

$$
\begin{aligned}
L_{\text {regional }, y=\text { mean }, m=2, a}= & L_{\text {regional }, \infty}-\left(L_{\text {regional }, \infty}-L_{\text {regional }, \text { hatch }}\right) \\
& \cdot \mathrm{e}^{g_{\text {regional }} \cdot A}
\end{aligned}
$$

to the entire North Sea data set of length and age collected during trawls surveys during January-March 1980-2003 to establish regional values of the asymptotic length $L_{\text {regional, } \infty}(197 \mathrm{~cm})$, length at hatching $L_{\text {regional,hatch }}(0.14 \mathrm{~cm})$ and regional mean growth rate $g_{\text {regional }}\left(0.1030 \mathrm{~cm} \mathrm{y}^{-1}\right)$. In this case the age $A$ is a continuous variable representing age from 1 January in the year in which the fish was born, i.e. $A=a+(m-0.5) / 12$. Assuming that the values of $L_{\text {regional, } \infty}$ and $L_{\text {regional,hatch }}$ were homogeneous in space, they then fitted spatially explicit values of the growth parameter $\left(g_{\text {rectangle }}\right)$ to the length and age data from each ICES statistical rectangle on the European shelf. After this process, there remained a significant proportion of rectangles with no or insufficient data to fit a value of $g$. Hence, a generalised additive model (GAM) was developed relating $\mathrm{g}$ to latitude, longitude and rectangle mean temperature over the period 1983-2003, and this was used to infill fitted values of $g$ where required. We averaged their values of $g_{\text {rectangle }}$ over all rectangles contained within each of the 10 natal areas of our model to produce a mean value for each natal population $\left(g_{n}\right)$. The predicted trajectories of the fastest growing (area 2, West Coast) and slowest growing (area 8, Fisher) natal populations are shown in Fig. A1. For each natal population, the length at age during any month of the year, was then given by:

$L_{n, y, m, a}=L_{\text {regional }, \infty}-\left(L_{\text {regional }, \infty}-L_{\text {regional,hatch }}\right) \cdot \mathrm{e}^{g_{n} \cdot A}$

In principle, variability in $g_{n}$ between annual cohorts could be accommodated in the model, but in this study we assumed that $g_{n}$ was fixed in time for each natal population. However, to investigate 


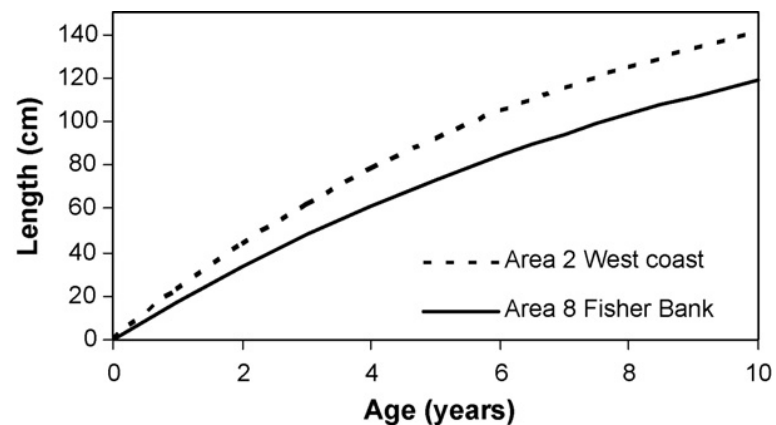

Fig. A1. Predicted changes in length of fish as continuous functions of age in the model, for the natal population of area 2 (West coast) and area 8 (Fisher).

the effects of changes in post-settlement development rate on the equilibrium output of the model, we applied a growth rate-scaling factor $(\Delta g)$ uniformly to the values of $g_{n}$.

Body length at age was converted to weight at age $(\mathrm{g})$ using a month-specific regional weight-length relationship (Coull et al., 1989):

Gutted weight $\left(\mathrm{Wg}_{n, y, m, a}\right)=\alpha_{m}\left(L_{n, a}\right)^{\beta}$

Total weight $\left(\mathrm{Wt}_{n, y, m, a}\right)=\mathrm{Wg}_{n, y, m, a} \times \mathrm{RF}$

where $\beta=2.8571, \alpha_{m}$ varied monthly with an annual mean of 0.0175 (Table A1 ), and RF=1.17.

The proportion of females mature at age was assumed to change in a stepwise fashion on 1 January each year. The regional (North Sea wide) mean female proportion mature at age $\left(Q_{\text {regional }, a}\right)$ was estimated from a Weibull distribution fitted to all of the annual age and maturity data from trawls surveys during January-March 1980-2003 in the North Sea, according to Andrews et al. (2006):

$Q_{\text {regional }, a}=1-\mathrm{e}^{((a / \delta) \cdot \varepsilon)}$

where $\delta=4.118$ and $\varepsilon=3.984$.

To parameterise the proportion mature on 1 January of fish of a given age in each natal population $\left(Q_{n, y, a}\right)$ we first estimated the global age $\left(A_{\text {global }_{n, y, m}}\right)$ corresponding to the length of fish on 1 January $\left(L_{n, y, m=0, a}\right)$, by means of the regionally fitted von Bertalanffy relationship:

$A_{\text {global }_{n, y, m=0, a}}=\frac{1}{g_{\text {regional }}} \cdot \ln \left(\frac{L_{\infty}-L_{\text {hatch }}}{L_{\infty}-L_{n, y, m=0, a}}\right)$

Then, the proportion mature was estimated as:

$Q_{n, y, a}=1-\mathrm{e}^{\left(\left(A_{\text {global }_{n, y}, m=0, a} / \delta\right) \cdot \varepsilon\right)}$

In the event that inter-cohort variability in growth rate was resolved in the model, the proportion mature at age for a given natal population was also potentially year-dependent. The predicted change in proportion mature at age for the fastest growing (area 2, west of Scotland) and slowest growing (area 8, Fisher Bank) natal populations are shown in Fig. A2, together with the average observed proportions mature at age for fish caught in each of these areas during the annual trawl surveys in February.

\section{A.2. Natural mortality rate}

Natural mortality rates ( $M$, being divided into $M_{\text {mature }}$ and $M_{\text {immature }}, \mathrm{m}^{-1}$ ) operated as a function of body length, but as for the estimation of proportion mature at age, was parameterised as a function of age since the data available for calibration were agebased. For both mature and immature fish the basic rate of natural mortality was assumed to vary with age according to a continuous function

$M=\kappa \cdot A^{\lambda}$

where $\kappa$ and $\lambda$ were constants and $A$ was the age (years) expressed as a continuous variable with $A=0$ on 1 January in the year in which a fish was born.

Hence, the mortality rate applicable over some age interval $A_{1}$ to $A_{2}$ was given by

$$
M_{\left(A_{1} \text { to } A_{2}\right)}=\int_{A_{1}}^{A_{2}} \kappa \cdot A^{\lambda} \cdot \mathrm{d} a=\frac{\kappa}{\lambda+1}\left(A_{2}^{(\lambda+1)}-A_{1}^{(\lambda+1)}\right)
$$

Setting $A_{2}=A_{1}+1$ year, initial values of $\kappa$ and $\lambda$ were derived by regression of log-transformed age and mortality, to provide the best fit of $M_{\left(A_{1} \text { to } A_{2}\right)}$ to the ICES Multi-Species Virtual Population Analysis (MSVPA) derived annual natural mortality rates of cod in the North Sea (Heath et al., 2003). The value of the exponent $\lambda$ was then adjusted such that the cumulative mortality between ages 1 and 10 of the exponential function equalled that from the MSVPA values. The outcome was $\kappa=1.0977$, and $\lambda=-0.8685$. So, for integer age $a$, to calculate the mortality rate applicable over month $m=1-12$, $A_{1}=a+((m-1) / 12)$ and $A_{2}=a+(m / 12)$.

Natal population dependence of natural mortality was introduced, as in the calculation of proportional maturity, by defining the ages $A_{1}$ and $A_{2}$ to correspond to values of $A_{\text {global }_{n, y, m, a}}$, i.e. the age corresponding to the length $\left(L_{n, y, m, a}\right)$ derived from the North Sea regional von Bertalanffy relationship. Hence, natural mortality rates at age varied between natal populations depending on growth rate, and could in principle be year-specific if inter-cohort variability in development rate was introduced.

For mature fish, the natural mortality rate $\left(M_{\text {mature }_{n, y, m, a}}\right)$ was taken to be equal to $M_{n, y, m, a}$ as derived above. However, an additional nursery area (c) and density dependent component was included in the natural mortality of immature fish $\left(M_{\text {immature }_{n, y, a, c}}\right)$ since there is clear observational evidence of predation on juvenile cod by adults (e.g. Floeter and Temming, 2003). Other predators may also be attracted to aggregations of juvenile cod leading to density dependent predation mortality.

We represented the density dependent component of mortality on immature cod, conceived as operating through cannibalistic predation by mature cod, by scaling the basic natural mortality at age by a factor $\left(\Lambda_{y, c}\right)$ which was a function of the abundance of all mature fish associated with the spawning are $(j)$ local to the nursery area $(c$, i.e. $j=c)$ on 1 January:

$M_{\text {immature }_{n, y, m \cdot a, c}}=M_{n, y, m \cdot a} \times \Lambda_{y, c}$

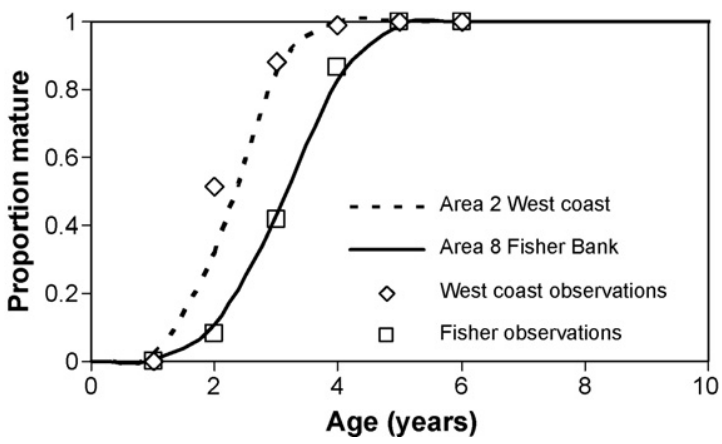

Fig. A2. Predicted and observed changes in proportion of females mature in February with incremental age, for the natal population of area 2 (West coast) and area 8 (Fisher). Observed data are averages over 1980-2000 for fish caught in each of the regions during the annual February/March trawl surveys. 
Table A1

Parameter descriptions and values in the model

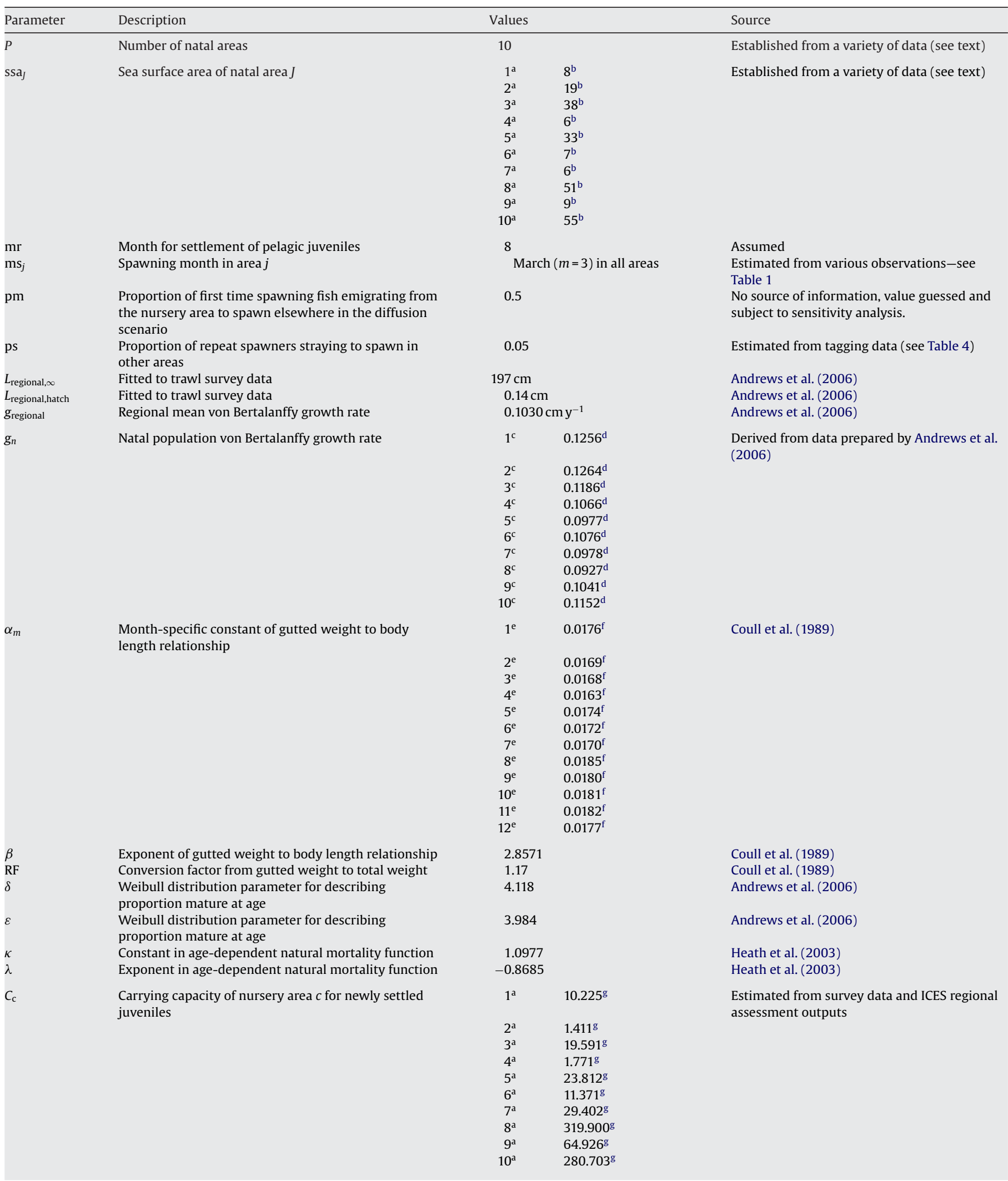




\begin{tabular}{|c|c|c|c|c|}
\hline Parameter & Description & Values & & Source \\
\hline \multirow[t]{10}{*}{$T_{j}$} & $\begin{array}{l}\text { Maximum observed spawning biomass in spawning } \\
\text { area } j\end{array}$ & $1^{\mathrm{a}}$ & $3,380^{\mathrm{h}}$ & Estimated from survey data \\
\hline & & $2^{\mathrm{a}}$ & $9,276^{\mathrm{h}}$ & \\
\hline & & $3^{a}$ & $24,639^{\mathrm{h}}$ & \\
\hline & & $4^{\mathrm{a}}$ & $11,811^{\mathrm{h}}$ & \\
\hline & & $5^{\mathrm{a}}$ & $12,0476^{\mathrm{h}}$ & \\
\hline & & $6^{a}$ & $6,914^{\mathrm{h}}$ & \\
\hline & & $7^{\mathrm{a}}$ & $3,506^{\mathrm{h}}$ & \\
\hline & & $8^{a}$ & $60,924^{\mathrm{h}}$ & \\
\hline & & $9^{a}$ & $9,948^{\mathrm{h}}$ & \\
\hline & & $10^{\mathrm{a}}$ & $39,133^{\mathrm{h}}$ & \\
\hline$t$ & $\begin{array}{l}\text { Threshold ratio of SSB on } 1 \text { January to maximum } \\
\text { observed SSB }\end{array}$ & 0.9 & & Hand fitted by exploratory analysis \\
\hline$p$ & $\begin{array}{l}\text { Exponent of density dependent immature mortality } \\
\text { scaling factor }\end{array}$ & 1.0 & & Hand fitted by exploratory analysis \\
\hline$V_{a}$ & Sex ratio of age class $a$ & 0.5 & & Assumed \\
\hline$\zeta$ & $\begin{array}{l}\text { Constant term of fecundity to gutted weight } \\
\text { relationship }\end{array}$ & 87.041 & & Adapted from West (1970) \\
\hline$\theta$ & Exponent of fecundity to gutted weight relationship & 1.248 & & Adapted from West (1970) \\
\hline$\varphi$ & Pelagic survival scaling factor & 1.3 & & Fitted \\
\hline$\Delta F$ & Regional fishing mortality rate scaling factor & $0.5-1.0$ & & Imposed to vary the forcing of the model. \\
\hline$\Delta g$ & Growth rate scaling factor & 1 & & $\begin{array}{l}\text { Available to be varied to reflect } \\
\text { post-settlement growth variability, but kept } \\
\text { constant in this paper. }\end{array}$ \\
\hline
\end{tabular}

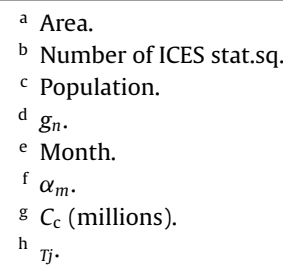

We defined the spawning biomass fraction on 1 January

$\mathrm{Bt}_{y, j}=\frac{\sum_{n=1}^{n=P} \sum_{a=0}^{a=20}\left(N_{\text {mature }_{n, y, m=0, a j}} \times \mathrm{Wt}_{n, y, m=0, a}\right)}{T_{j}}$

Then,

$\Lambda_{y, c}=1$

when $\mathrm{Bt}_{y, j} \leq t$, where $c=j$

$\Lambda_{y, c}=\left(1+\left(\mathrm{Bt}_{y, j}-t\right)\right)^{p}$

when $\mathrm{Bt}_{y, c}>t$, where $c=j T_{j}$ represented the historical maximum observed spawning biomass of fish in a given spawning area, and the parameter $t$ represented a threshold fraction of this biomass above which the mortality rate on immature fish in the local nursery area becomes dependent on spawning biomass.

The parameters $t=0.9$ and $p=1.0$ were fitted such that equilibrium regional spawning biomass (SSB) at half the 1980-1999 average regional fishing mortality rate was within $5 \%$ of the maximum observed SSB since 1963.

The values of $T_{j}$, were estimated by distributing the maximum regional SSB since 1963 (252,712 tonnes in 1971) across spawning areas in proportion to the mean distribution of age 4 area integrated catch per unit effort from the February/March trawl surveys (see section on 'Spatially and temporally distributed fishing mortality' in the body of the text).

\section{A.3. Egg production}

We specify a spawning month $\left(\mathrm{ms}_{j}\right)$ for each natal area. In the middle of that month, the mature females which have adopted each spawning area will shed their annual egg production, calculated as the sum over all natal origins of female fecundity. The model accommodates differences in spawning months between sub-units.

Natural mortality at age between start and mid-point of spawning month $\mathrm{ms}_{j}$ is given by

$$
\begin{aligned}
M_{\text {mature-mid }_{(n, y, \mathrm{~ms}, a)}=} & \frac{\kappa}{\lambda+1} \times\left(\left(A_{\text {global }_{n, y, \mathrm{~ms}-1, a}}\right)^{(\lambda+1)}\right. \\
& \left.-\left(A_{\text {global }_{n, y, \mathrm{~ms}, a}}\right)^{(\lambda+1)}\right)
\end{aligned}
$$

The numbers of spawning female fish of age $a$ in year $y$ for a given spawning location $j$ are given by

$$
\begin{aligned}
N_{\text {spawning }_{(n, y, \mathrm{~ms}, a j)}=} & \exp \left(\ln \left(Q_{(n, y, a)} \times V_{(a)} \times N_{(n, y, \mathrm{~ms}-1, a, j)}\right)\right. \\
& \left.-M_{\text {mature-mid }_{(n, y, \mathrm{~ms}, a)}}-\frac{\mathrm{Fs}_{(j, y, a)}}{2}\right)
\end{aligned}
$$

where $V_{a}$ is the sex ratio as a function of age which in this study was assumed to be 0.5 across all ages and populations. Population egg production in year $y$ for a given spawning location $j,\left(\mathrm{EP}_{(y, j)}\right)$ was thus:

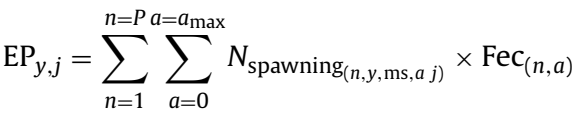

We defined annual fecundity $\left(\mathrm{Fec}_{n, a}\right)$ in terms of gutted wet weight $\left(\mathrm{Wg}_{a}\right)$ in March based on a published relationship for North Sea cod (Marteinsdottir and Begg, 2002; Yoneda and Wright, 2004):

$\operatorname{Fec}_{(n, a)}=\zeta \times\left(\mathrm{Wg}_{(n, a)}\right)^{\theta}$

where $\zeta=87.0414, \theta=1.248$, and $\mathrm{Wg}=$ gutted weight $(\mathrm{g})$. 


\section{A.4. Early life stage dispersal and survival}

We used an off-line particle-tracking model to simulate the transport of eggs and larvae from the spawning rectangles of each natal area to the various nursery areas. The basic model has previously been described by Gallego and Heath (2003), Heath and Gallego (1998, 2000) and Heath et al. (2003). Briefly, the model covered the European shelf $\left(50^{\circ} \mathrm{N}, 15^{\circ} \mathrm{W}\right.$ to $\left.65^{\circ} \mathrm{N}, 15^{\circ} \mathrm{E}\right)$ and utilised date-specific daily mean wind-driven currents from the Statistical North Atlantic Circulation (SNAC) model ( $14 \mathrm{~km}$ horizontal resolution and 5 layers in the upper $150 \mathrm{~m}$; Logemann et al., 2004), hourly M2 tidal velocities from Hamburg Shelf Ocean Model (HAMSOM; Backhaus, 1985; Backhaus and Hainbucher, 1987), and date-specific monthly mean 3-dimensional temperature fields from a statistical model of observational data $(55 \mathrm{~km}$ horizontal resolution and 5 layers in the upper $150 \mathrm{~m}$; Heath et al., 2003). Particles, representing fish eggs, were launched in the model at specific dates and locations, and their trajectories in space and time due to advection and horizontal diffusion calculated at hourly intervals. The particles had time-varying vertical distributions related to their simulated body size (see below) but were passive with respect to horizontal transport. Temperature along each particle drift track was used to simulate first, the development and hatching of eggs, and then the growth and mortality of larvae. Parameters of the relationship between temperature and growth rate were derived from analysis of daily age and length of field sampled larvae, and mortality rate was parameterised as a function of length. Thus faster growing larvae experienced higher relative survival during development over a given interval of body size than slow growing larvae.

To derive, for a given year, the probability of drift and survival of progeny from a given spawning area in our model to each of the nursery areas, we launched 5 particles per $1 / 8^{\circ}$ latitude and $1 / 4^{\circ}$ longitude interval distributed over each of the sets of rectangles assigned as spawning locations, on each day of the spawning season. Taking all 10 spawning areas together, this represented 401,380 particles per year. The start and end dates of the spawning season were specified for each spawning area, and the proportion of the annual egg production shed each day was represented by a Gaussian curve with standard deviation equal to $1 / 6$ of the spawning season duration. Each particle was assigned a weighting at release, corresponding to its proportional contribution to the spawning area annual egg production (i.e. proportion of area-specific annual egg production on a given date divided equally amongst the number of particles released from the area on that day). We tracked each particle until the simulated larvae it represented attained a length of $35 \mathrm{~mm}$, assumed to be the size at which cod seek to settle on the seabed. Once all particles had reached this settlement size, the drift probability from each spawning area to each nursery area $\left(D_{y j, c}\right)$ was calculated as the sum of initial egg production weightings of particles reaching the given nursery area from a given spawning area ("successful particles"), divided by the sum of initial weightings of all particles released in a spawning area during the season. These probabilities did not sum to unity for each spawning area, because some particles were not located above nursery rectangles at the point of settlement and were lost from the system. The initial egg production weighting of each particle was depleted each day according to the simulated mortality rate. The ratio of the remaining weighting at $35 \mathrm{~mm}$ to the initial egg production weighting of a particle represented the cumulative mortality along the drift trajectory. The simulated survival of all progeny drifting from each spawning area to each nursery area $\left(\Pi_{y, j, c}\right)$ was then the sum of weightings at $35 \mathrm{~mm}$ of successful particles, divided by the initial egg production weightings of the same successful particles. We treated this survival terms as a relative index and applied a constant scaling factor $(\varphi)$ to all such indices, which we treated as a fitting parameter, to adjust the absolute level of recruitment to be consistent with the production and abundance of the mature spawning stock.

The total number of pelagic juveniles arriving at a given nursery area $(c)$ in year $(y)$ was then:

$\sum_{j=1}^{j=P} \mathrm{EP}_{y, j} \cdot D_{y, j, c} \cdot \Pi_{y, j, c} \cdot \varphi$

At each of these nursery areas, only a proportion of surviving pelagic juveniles were allowed to recruit to the young-of-the-year 0 -age class of each of the contributing natal populations. This proportion was dependent on the ratio of the numbers of pelagic juveniles which had been transported to the nursery area (from all natal sources), and the carrying capacity of the area. If the number of pelagic juveniles was less then the carrying capacity then all were recruited to the contributing age structured populations. If the carrying capacity was exceeded, then numbers recruiting to each natal population were reduced proportionately so that the total number settling equalled the carrying capacity. The carrying capacity of each nursery area was thus a key parameter setting the maximum level of recruitment to the populations. In addition, the recruitment patterns of the natal population were interdependent since the populations effectively competed with each other for the available carrying capacity in the nursery areas.

We estimated the carrying capacity of each nursery area $\left(C_{\mathrm{c}}\right)$ from a combination of February/March trawl survey data from the North Sea (ICES area IV) and west of Scotland (ICES area VI), and ICES regional assessment outputs of numbers at age taking discards into account. For each survey year, we estimated the proportion of the regionally integrated abundance of age 1 cod (i.e. fish born in the preceding year) which were caught in each natal area. These proportions were then averaged over the survey series (North Sea 1983-2005, West of Scotland 1985-2005) and applied to the maximum of a smoother (LOESS) through the time series of regional numbers at age 1 from the assessment outputs (North Sea maximum occurred in 1979, West of Scotland maximum in 1982). These maximum observed numbers at age 1 in each area were then inflated to numbers in August the previous year (i.e. at settlement time) using the growth and natural mortality trajectories for each natal population to provide an estimate of the carrying capacity for newly settled juveniles.

\section{References}

Andrews, J.M., Gurney, W.S.C., Heath, M.R., Gallego, A., O’Brien, C.M., Darby, C., Tyldesley, G., 2006. Modelling the spatial demography of cod on the European continental shelf. Can. J. Fish. Aquat. Sci. 63, 1027-1048.

Anon., 2000. Council Regulation (EC) No. 2549/2000 of 17 November 2000 establishing additional technical measures for the recovery of the stock of cod in the Irish Sea (ICES Division VIIa). Official J. Eur. Commun. L292/5.

Anon. 2001. Commission Regulation (EC) No. 259/2001 of 7 February 2001.Establishing measures for the recovery of the stock of cod in the North Sea (ICES subarea IV) and associated conditions for the control of activities of fishing vessels. Official J. Eur. Commun. L39/7.

Anon., 2004. Council Regulation (EC) No. 423/2004 of 26 February 2004 establishing measures for the recovery of cod stocks. Official J. Eur. Commun. L70/8.

Backhaus, J.O., 1985. A three-dimensional model for the simulation of shelf sea dynamics. Deut hydrographische Z. 38, 165-187.

Backhaus, J.O., Hainbucher, D., 1987. A finite difference general circulation model for shelf seas and its application to low frequency variability on the North European Shelf. In: Nihoul, J.C., Jamart, B.M. (Eds.), Three Dimensional Models of Marine and Estuarine Dynamics. Elsevier Oceanography Series 45, pp. 221-244.

Beaugrand, G., Brander, K.M., Lindley, J.A., Souissi, S., Reid, P.C., 2003. Plankton effect on cod recruitment in the North Sea. Nature 426, 661-664.

Brander, K.M., 1994. The location and timing of cod spawning around the British Isles. ICES J. Mar. Sci. 51, 71-89.

Brander, K., Mohn, R., 2004. Effect of the North Atlantic Oscillation on recruitment of Atlantic cod (Gadus morhua). Can J. Fish. Aquat. Sci. 61, 1558-1564. 
Bryant, A.D., Heath, M.R., Gurney, W.S.C., Beare, D.J., Robertson, W., 1997. The seasonal dynamics of Calanus finmarchicus: development of a 3-dimensional structured population model and application to the northern North Sea. J. Sea Res. 38, 361-380.

Carroll, J.D., Arabie, P., 1980. Multidimensional scaling. In: Rosenzweig, M.R., Porter, L.W. (Eds). Ann. Rev. Psychol. 31, 607-649.

Child, A.R., 1988. Population genetics of cod (Gadus morhua (L.)), haddock (Melanogrammus aeglefinus (L.)), whiting (Merlangius merlangus (L.)) and saithe (Pollachius virens (L.)). MAFF Fish. Res. Technol. Rep. 87, 1-27.

Clarke, R.A., Fox, C.J., Viner, D., Livermore, M., 2003. North Sea cod and climate change-modelling the effect of temperature on population dynamics. Global Change Biol. 9, 1669-1680.

Cleveland, W.S., Grosse, E., Shyu, W.M., 1992. Local regression models. In: Chambers J.M., Hastie, T.J. (Eds.), Statistical Models. Wadsworth \& Brooks/Cole, Chapter 8

Cook, R.M., Heath, M.R., 2005. The implications of warming climate for the management of North Sea demersal fisheries. ICES J. Mar. Sci. 62, 1322-1326.

Cook, R.M., Sinclair, A., Stefánsson, G., 1997. Potential collapse of North Sea cod stocks. Nature 385, 521-522.

Coull, K.A., Jermyn, A.S., Newton, A.W., Henderson, G.I., Hall, W.B., 1989. Length/weight relationships for 88 species of fish encountered in the north east Atlantic. Scottish Fisheries Research Report 43, 81 pp.

Cushing, D.H., 1984. The gadoid outburst in the North Sea. J. Cons. Cons. Int. Explor. Mer. 41, 159-166.

de Roos, A., 1997. A gentle introduction to physiologically structured population models. In: Taljapurkar, S., Caswell, H. (Eds.), Structured Population Models in Marine, Terrestrial and Freshwater Systems. Chapman and Hall, New York.

Diekmann, O., Gyllenberg, M., Metz, J.A.J., Thieme, H.R., 1998. On the formulation and analysis of general deterministic structured population models. I. Linear theory. J. Math. Biol. 36, 349-388.

Faith, D.P., Minchin, P., Belbin, L., 1987. Compositional dissimilarity as a robust measure of ecological distance. Vegetatio 69, 57-68

Frank, K.T., Brickman, D., 2000. Allee effects and compensatory population dynamics within a stock complex. Can. J. Fish. Aquat. Sci. 57, 513-517.

Floeter, J., Temming, A., 2003. Explaining diet composition of North Sea cod (Gadus morhua): prey size preference vs. prey availability. Can. J. Fish. Aquat. Sci. 60 $140-150$

Gallego, A., Heath, M.R., 2003. The potential role of gadoid settlement on the stockrecruitment relationship: numerical experiments using bio-physical modelling simulations. ICES CM P:11, 14 pp.

Galley, E.A., Wright, P.J., Gibb, F.M., 2006. Combined methods of otolith shape analysis improve identification of spawning areas of Atlantic cod. ICES J. Mar. Sci. 63 , $1710-1717$.

Gibb, F.M., Gibb, I.M., Wright, P.J., 2007. Isolation of Atlantic cod (Gadus morhua) nursery areas. Mar. Biol. 151, 1185-1194.

Gopalsamy, K., 1997. Age dependent population dispersion in linear habitats. Ecol Modell. 3, 119-132.

Gupta, S., Lonsdale, D.J., Wang, D.-P., 1994. The recruitment patterns of an estuarine copepod: a biological-physical model. J. Mar. Sci. 52, 687-710.

Gurney, W.S.C., Nisbet, R.M., 1998. Ecological Dynamics. Oxford University Press, New York.

Gurney, W.S.C., Speirs, D.C., Wood, S.N., Clarke, E.D., Heath, M.R., 2001. Simulating spatially and physiologically structured populations. J. Anim. Ecol. 70, 881-894

Heath, M.R., Baird, D.L., 1983. Recruitment and seasonal migrations of herring to the west of Scotland. ICES CM H:51, 25 pp.

Heath, M.R., Gallego, A., 1998. Biophysical modelling of the early life stages of haddock in the North Sea. Fish. Oceanogr. 7, 110-125.

Heath, M., Gallego, A., 2000. Modelling the spatial and temporal structure of survivorship to settlement in North Sea and west of Scotland haddock. ICES CM $\mathrm{N}: 11,17 \mathrm{pp}$

Heath, M.R., MacKenzie, B.R., Ådlandsvik, B., Backhaus, J.O., Begg, G.A., Drysdale, A., Gallego, A., Gibb, F., Gibb, I., Harms, I.H., Hedger, R., Kjesbu, O.S., Logemann, K., Marteinsdottir, G., McKenzie, E., Michalsen, K., Nielsen, E., Scott, B.E., Strugnell, G., Thorsen, A., Visser, A., Wehde, H., Wright, P.J., 2003. An operationa model of the effects of stock structure and spatio-temporal factors on recruitment. Final report of the EU-STEREO project. FAIR-CT98-4122. 1 Decembe 1998-28 February 2002. Fisheries Research Services Contract Report No. 10/03, 360 pp.

Holmes, S.J., Wright, P.J., Fryer, R.J., 2008. Evidence for regional variability in cod dynamics in the North Sea and West of Scotland from survey data. ICES J. Mar. Sci. 65, 206-215.

Hutchinson, W.F., Oosterhout, C.V., Rogers, S.I., Carvalho, G.R., 2003. Temporal analysis of archived samples indicates marked genetic changes in declining North Sea cod (Gadus morhua). Proc. R. Soc. Lond. B 270, 2125-2132.

Hutchinson, W.F., Carvalho, G.R., Rogers, S.I., 2001. Marked genetic structuring in localised spawning populations of cod Gadus morhua in the North Sea and adjoining waters, as revealed by microsatellites. Mar. Ecol. Prog. Ser. 223 , 251-260.

ICES, 2003. Report of the ICES Advisory Committee on Fishery Management, 2002. ICES Co-op. Res. Rep. 255. Copenhagen.

ICES, 2005. Report of the Working Group on the Assessment of Northern Shelf Demersal Stocks. ICES Document, CM 2005/ACFM:15, http://www. ices.dk/reports/ACFM/2005/WGNSSK/.

ICES, 2006. Report of the Working Group on the Assessment of Demersal Stocks in the North Sea and Skagerrak. ICES Document, CM 2005/ACFM:09, http://www.ices.dk/reports/ACFM/2005/WGNSDS/.
Jamieson, A., Thompson, D., 1972. Blood proteins in North Sea cod (Gadus morhua L.). In: Kovacs, G., Papp, M. (Eds.), Proceedings of the 12th European Conference on animal blood groups and biochemical polymorphism. Dr. W. Junk, The Hague, pp. 585-591.

Jørgensen, C., Enberg, K., Dunlop, E.S., Arlinghaus, R., Boukal, D.S., Brander, K., Ernande, B., Gårdmark, A., Johnston, F., Matsumura, S., Pardoe, H., Raab, K., Silva, A., Vainikka, A., Dieckmann, U., Heino, M., Rijnsdorp, A.D., 2007. Managing evoloving fish stocks. Science 318, 1247-1248.

Kruskal, J.B., Wish, M., 1978. Multidimensional Scaling. Sage Publications, Beverley Hills, CA

Kurlansky, M., 1999. Cod. A Biography of the Fish that Changed the World. Vintage, London, $294 \mathrm{pp}$.

Logemann, K., Backhaus, J.O., Harms, I.H., 2004. SNAC: a statistical model of the North Atlantic circulation. Ocean Model. 7, 97-110.

Magurran, A.E., 1988. Ecological Diversity and its Measurement. Princeton University Press, Princeton, NJ

Marteinsdottir, G., Begg, G., 2002. Essential relationships incorporating the influence of age, size and condition on variables required for estimation of reproductive potential in Atlantic cod Gadus morhua stocks. Mar. Ecol. Prog Ser 235, 235-256.

McKendrick, A.C., 1926. Applications of mathematics to medical problems. P. Edinburgh Math. Soc. 44, 98-130.

Metcalfe, J.D., Fox, C.J., Righton, D.A., Wright, P.J., Casey, J., 2005. A review of the biological evidence for cod stock sub-structure in the North Sea. Working Paper Report from a Joint CEFAS/FRS Workshop, STECF Meeting on 'Cod recovery plan' Ispra, 13-17 June 2005, 46 pp.

Mollison, D., 1991. Dependence of epidemic and population velocities on basic parameters. Math. Biosci. 107, 255-287.

Neat, F.C., Wright, P.J., Zuur, A.F., Gibb, I.M., Gibb, F.M., Tulett, D., Righton, D.A., Turner, R.J., 2006. Residency and depth movement of a coastal group of Atlantic cod (Gadus morhua L.). Mar. Biol. 148, 643-654.

Neubert, M.G., Caswell, H., 2000. Demography and dispersal: calculation and sensitivity analysis of invasion speed for structured populations. Ecology 81 , 1613-1628.

O’Brien, C.M., Fox, C.J., Planque, B., Casey, J., 2000. Climate variability and North Sea cod. Nature 404, 142.

Olsen, E.M., Knutsen, H., Gjøsæter, J., Jorde, P.E., Knutsen, J.A., Stenseth, N.C., 2004 Life-history variation among local populations of Atlantic cod from the Norwegian Skagerrak coast. J. Fish. Biol. 64, 1725-1730.

Perry, A.L., Low, P.J., Ellis, J.R., Reynolds, J.D., 2005. Climate change and distribution shifts in marine fishes. Science 308 (5730), 1912-1915.

Perutz, M., 2007. Population variation in the life history traits and thermal responses of Atlantic cod, Gadus morhua L. Ph.D. Thesis. University of Glasgow, 223 pp.

Planque, B., Frédou, T., 1999. Temperature and the recruitment of Atlantic cod (Gadus morhua). Can. J. Fish. Aquat. Sci. 56, 2069-2077.

R Development Core Team 2005. R: A language and environment for statistical computing. R Foundation for Statistical Computing, Vienna, Austria. ISBN:3900051-07-0, http://www.R-project.org.

Reid, J.M., Bignal, E.M., Bignal, S., McCracken, D.I., Monaghan, P., 2006. Spatial variation in demography and population growth rate: the importance of natal location. J. Anim. Ecol. 75, 1201-1211.

Ricker, W.E., 1975. Computation and interpretation of biological statistics of fish populations. Fish. Res. Board Can Bull., 191.

Righton, D., Quayle, V., Hetherington, S., Burt, G., 2007. Movements and distribution of cod in the southern North sea and English Channel: results from conventional and electronic tagging experiments. J. Mar. Biol. Assoc. UK 87, 599-613.

Rindorf, A., Lewy, P., 2006. Warm, windy winters drive cod north and homing of spawners keeps them there. J. Appl. Ecol. 43, 445-453.

Robichaud, D., Rose, G.A., 2001. Multiyear homing of Atlantic cod to a spawning ground. Can. J. Fish. Aquat. Sci. 58, 2325-2329.

Robichaud, D., Rose, G.A., 2004. Migratory behaviours and range in Atlantic cod: inference from a century of tagging. Fish Fisheries 5, 185-214.

Rochet, M.J., 1998. Short-term effects of fishing on life history traits of fishes. ICES J. Mar. Sci. 55, 371-391.

Rochet, M.J., Cornillon, P.A., Sabatier, R., Pontier, D., 2000. Comparative analysis of phylogenetic and fishing effects in life history patterns of teleost fishes. Oikos $91,255-270$

Rose, G.A., 2004. Reconciling overfishing and climate change with stock dynamics of Atlantic cod (Gadus morhua) over 500 years. Can. J. Fish. Aquat. Sci. 61, 1553-1557.

Sinclair, M., 1988. Marine populations. An essay on population regulation with speciation. Washington Sea Grant Program, 252 pp.

Sokal, R.R., Rohlf, F.J., 1995. Biometry. Freeman, New York, 887 pp.

Stocker, M.V., Haist, V., Fournier, D., 1985. Environmental variation and recruitment of Pacific herring (Clupea harengus pallasi) in the Strait of Georgia. Can. J. Fish. Aquat. Sci. 42 (Suppl. 1), 174-180.

Svedäng, H., Svenson, A., 2006. Cod (Gadus morhua L.) populations as behavioural units: inference from time series on juvenile cod abundance in the Skagerrak. J. Fish Biol 69 (Suppl. C), 1-14.

Svedäng, H., Righton, D., Jonsson, P., 2007. Migratory behaviour of Atlantic cod Gadus morhua: natal homing is the prime stock-separating mechanism. Mar. Ecol. Prog. Ser. 345, 1-12

Valiente, A.G., Juanes, F., Garcia-Vazquez, E., 2005. Reproductive strategies explain genetic diversity in Atlantic Salmon, Salmo salar. Environ. Biol. Fish. 74, 323-334.

Van den Bosch, F., Metz, J.A.J., Diekmann, O., 1990. The velocity of spatial population expansion. J. Math. Biol. 28, 529-565. 
Verspoor, E., O'Sullivan, M., Arnold, A.L., Knox, D., Amiro, P.G., 2002. Restricted matrilineal gene flow and regional differentiation among Atlantic salmon (Salmo salar L.) populations within the Bay of Fundy, eastern Canada. Heredity 89, 465-472.

von Bertalanffy, L., 1938. A quantitative theory of organic growth (Inquiries on growth laws II). Hum. Biol. 10, 181-213.

von Foerster, H., 1959. Some remarks on changing populations. In: Stohlman, F. (Ed.), Kinetics of Cellular Proliferation. Grune and Stratton, New York.

West, W.Q.-B., 1970. The spawning biology and fecundity of cod in Scottish waters. Ph.D. Thesis, University of Aberdeen, 257 pp.
Wright, PJ., Gibb, F.M., Gibb, I.M., Heath, M.R., McLay, H.A., 2003. North Sea cod spawning grounds. Fisheries Research Services Internal Report No. 17/03, 6 pp. Wright, P.J., Galley, E., Gibb, I.M., Neat, F.C., 2006a. Fidelity of adult cod to spawning grounds in Scottish waters. Fish. Res. 77, 148-158.

Wright, P.J., Neat, F.C., Gibb, F.M., Gibb, I.M., Thoradarson, H., 2006b. Evidence for metapopulation structuring in cod from the west of Scotland and North Sea. J. Fish Biol. 69 (Suppl. C), 181-199.

Yoneda, M., Wright, P.J., 2004. Temporal and spatial variation in reproductive investment of Atlantic cod, Gadus morhua, in the northern North Sea and Scottish west coast. Mar. Ecol. Prog. Ser. 276, 237-248. 